\title{
Effect of halogen substitution on the enthalpies of solvation and hydrogen bonding of organic solutes in chlorobenzene and 1,2-dichlorobenzene derived using multi-parameter correlations
}

Mikhail A. Varfolomeev ${ }^{\text {, Ilnaz T. Rakipova }}{ }^{\text {a }}$ Artashes A. Khachatrian ${ }^{\text {a }}$, William E. Acree, Jr., , , Michela Brumfield ${ }^{b}$, and Michael H. Abraham ${ }^{\mathrm{c}}$

${ }^{a}$ Department of Physical Chemistry, Kazan Federal University, Kremlevskaya 18, Kazan, 420008, Russia

${ }^{b}$ Department of Chemistry, 1155 Union Circle \# 305070, University of North Texas, Denton, TX 76203-5017 (U.S.A.)

${ }^{c}$ Department of Chemistry, University College London, 20 Gordon Street, London, WC1H OAJ (U.K.)

\begin{abstract}
Enthalpies of solution at infinite dilution at $298 \mathrm{~K}, \Delta_{\text {soln }} H^{\mathrm{A} / \text { Solvent }}$, have been measured by isothermal solution calorimetry for 43 and 72 organic solutes dissolved in chlorobenzene and 1,2-dichlorobenzene, respectively. The measured $\Delta_{\text {soln }} H^{\mathrm{A} / \text { Solvent }}$ data, along with published $\Delta_{\text {soln }} H^{\mathrm{A} / \text { Solvent }}$ values taken from the published literature for solutes dissolved in both chlorobenzene solvents, were converted to enthalpies of solvation, $\Delta_{\text {solv }} H^{\mathrm{A} / \text { solvent }}$, using standard thermodynamic equations. Abraham model correlations were developed from the experimental $\Delta_{\text {solv }} H^{\mathrm{A} / \mathrm{Solvent}}$ data. The best derived correlations describe the experimental gas-to-chlorobenzene and gas-to-1,2-dichlorobenzene enthalpies of solvation to within standard deviations of $1.5 \mathrm{~kJ} \mathrm{~mol}^{-1}$ and $1.9 \mathrm{~kJ} \mathrm{~mol}^{-1}$, respectively. Enthalpies of $\mathrm{X}-\mathrm{H} \ldots \pi(\mathrm{X}-\mathrm{O}, \mathrm{N}$, and C) hydrogen bond formation of proton donor solutes (alcohols, amines, chlorinated hydrocarbons and etc.) with chlorobenzene and 1,2-dichlorobenzene were calculated based on the Abraham solvation equation. Obtained values are in good agreement with the results determined using conventional methods.
\end{abstract}

Key Words: Enthalpy of solution; enthalpy of solvation; chlorobenzene; 1,2-dichlorobenzene; molecular interactions; hydrogen bonding

Corresponding author: e-mail: acree@unt.edu, fax: 940-565-4318. 


\section{Introduction}

This study continues our combined experimental and theoretical examination of gas-toorganic solvent transfer processes for nonelectrolyte solutes [1-19]. Such processes govern chemical separations by gas-liquid chromatography, measurement of solubilities and activity coefficients by inert-gas stripping methods, and the removal and pre-concentration of volatile organic solutes from aqueous analytical samples using headspace single drop micro-extraction methods. The latter extraction process involves two partition coefficients, the first for solute transfer to the gas phase from the aqueous solution being analyzed, and the second for solute transfer into the suspended liquid drop of the micro-extraction device. A complete understanding of the solute transfer process requires not only examining how the equilibrium partition coefficient depends on the polarity and hydrogen-bonding character of the solute and solvent molecules, but also on understanding the enthalpic effects that determine how the gas-to-organic solvent partition coefficients of the different solute-solvent combinations vary with temperature.

In previous publications [1-15] we have developed Abraham model correlations:

$$
\begin{aligned}
& \Delta_{\text {solv }} H^{\mathrm{A} / \text { Solvent }}=c_{\mathrm{h}, \mathrm{l}}+\mathrm{e}_{\mathrm{h}, \mathrm{l}} \cdot \mathbf{E}+\mathrm{s}_{\mathrm{h}, \mathrm{l}} \mathbf{S}+\mathrm{a}_{\mathrm{h}, \mathrm{l}} \cdot \mathbf{A}+\mathrm{b}_{\mathrm{h}, \mathrm{l}} \cdot \mathbf{B}+\mathrm{l}_{\mathrm{h}, \mathrm{l}} \cdot \mathbf{L} \\
& \Delta_{\text {solv }} H^{\mathrm{A} / \text { Solvent }}=\mathrm{c}_{\mathrm{h}, \mathrm{v}}+\mathrm{e}_{\mathrm{h}, \mathrm{v}} \cdot \mathbf{E}+\mathrm{s}_{\mathrm{h}, \mathrm{v}} \cdot \mathbf{S}+\mathrm{a}_{\mathrm{h}, \mathrm{v}} \cdot \mathbf{A}+\mathrm{b}_{\mathrm{h}, \mathrm{v}} \cdot \mathbf{B}+\mathrm{v}_{\mathrm{h}, \mathrm{v}} \cdot \mathbf{V}
\end{aligned}
$$

for mathematically describing experimental enthalpies of solvation, $\Delta_{\text {solv }} H^{\mathrm{A} / \text { Solvent }}$, of inert gases and organic vapors dissolved in water and in a wide range of organic solvents of varying polarity and hydrogen bonding character. The organic solvents included several saturated hydrocarbons [1,2] and aromatic hydrocarbons [1,3,4], chlorinated alkanes [4-6], several primary, secondary and tertiary alcohols [7-11], two dialkyl carbonates [12], one alkyl acetate solvent [13], one dialkyl ether [13] and two cyclic ethers [6,8], as well as several miscellaneous organic solvents $[9,14,15]$. In each case eqns. (1) and (2) were found to provide a reasonably accurate 
mathematical description of the experimental enthalpy of solvation data. For each solvent the differences between the experimental and back-calculated $\Delta_{\text {solv }} H^{\mathrm{A} / \text { Solvent }}$ values were on the order of $\pm 3 \mathrm{~kJ} \mathrm{~mol}^{-1}$ or less.

The Abraham model is a linear free energy relationship that has been used to describe a large number of solute transfer processes involving two liquid phases [20-24], blood and body fluids/organs/tissues [25-29], water and molecularly organized solvent media (micellar solutions) [30, 31], and gas and condensed liquid or solid phases [20-25, 27, 28, 30-32]. The same mathematical form is used to describe each solute transfer process, the only difference being that $\Delta_{\text {solv }} H^{\mathrm{A} / \text { Solvent }}$ is replaced by the solute transfer property being described (e.g., gas-to-liquid partition coefficient, water-to-liquid partition coefficient, blood-to-brain partition coefficient, gas-to-brain partition coefficient, etc.). Each term in eqns. (1) and (2) represents a different type of molecular interaction involving the solute and its solubilizing media. The interactions are expressed as the product of a solute property times the complimentary solvent property. Molecular solute descriptors contain important information regarding the ability of the dissolved solute to interact with its surrounding solubilizing media. Solute descriptors are defined as follows: $\mathbf{E}$ is the solute excess molar refractivity in units of $\left(\mathrm{cm}^{3} \mathrm{~mol}^{-1}\right) / 10, \mathbf{S}$ is the solute dipolarity/polarizability, $\mathbf{A}$ and $\mathbf{B}$ are the overall or summation hydrogen-bond acidity and basicity, $\mathbf{V}$ is the McGowan volume in units of $\left(\mathrm{cm}^{3} \mathrm{~mol}^{-1}\right) / 100$, and $\mathbf{L}$ is the logarithm of the gas-to-hexadecane partition coefficient at $298 \mathrm{~K}$. The complimentary solubilizing media properties are identified in eqns. (1) and (2) by the lower case alphabetic letters that immediately precede the solute descriptors. Numerical values of the solvent properties are determined by solving a series of equations generated from measured solute transfer properties for solutes with known solute descriptors. The $a_{h, 1}$ equation coefficients for benzene, mesitylene and p-xylene were recently used [3] to examine weak $\mathrm{X}-\mathrm{H} \ldots \pi(\mathrm{X}-\mathrm{O}, \mathrm{N}$, and $\mathrm{C})$ hydrogen bonding of 
aromatic solvents with different proton donors. Hydrogen-bonding enthalpies calculated as the product of $\mathrm{a}_{\mathrm{h}, \mathrm{l}} \cdot \mathbf{A}\left(\right.$ e.g., $\left.\Delta_{\mathrm{HB}} \mathrm{H}^{0}=\mathrm{a}_{\mathrm{h}, \mathrm{l}} \cdot \mathbf{A}\right)$ were in good agreement with values calculated using the Solomonov et al method [33]. Two independent models, the Abraham model and Solomonov et al. model, yielded comparable hydrogen-bonding enthalpies.

In the present study we extended our enthalpic considerations to include both chlorobenzene and 1,2-dichlorobenzene. Enthalpies of solution have been measured calorimetrically for 43 different organic solutes dissolved in chlorobenzene, and for 72 different organic solutes dissolved in 1,2-dichlorobenzene at $298.15 \mathrm{~K}$. The measured enthalpies of solution, $\Delta_{\text {soln }} \mathrm{H}^{0}$, are converted into enthalpies of solvation by subtracting the solute's molar enthalpy of vaporization or molar enthalpy of sublimation, $\Delta_{\text {solv }} H^{\mathrm{A} / \text { Solvent }}=\Delta_{\text {soln }} H^{\mathrm{A} / \text { Solvent }}-\Delta_{\text {vap }} H^{0}$ and $\Delta_{\text {solv }} H^{\mathrm{A} / \text { Solvent }}=\Delta_{\text {soln }} H^{\mathrm{A} / \text { Solvent }}-\Delta_{\text {sub }} H^{0}$, depending on whether measured $\Delta_{\text {soln }} H^{\mathrm{A} / \text { Solvent }}$ value pertained to a liquid or crystalline solute. Abraham model $\Delta_{\text {solv }} H^{\mathrm{A} / \text { Solvent }}$ correlations for both chlorobenzene and 1,2-dichlorobenzene were derived by combining our measured experimental data with published $\Delta_{\text {soln }} H^{\mathrm{A} / \text { Solvent }}$ and $\Delta_{\text {solv }} H^{\mathrm{A} / \text { Solvent }}$ data taken from the chemical literature [3465].

Thermodynamic studies in chloroaromatic hydrocarbon solvents can be informative in that halogen-bond formation may occur [66-68]. Halogen bonds can be represented as RX …..:YZ type specific interactions where $\mathrm{RX}$ is generally either an alkyl halide or aromatic halide $(\mathrm{X}=\mathrm{Cl}$, $\mathrm{Br}, \mathrm{I})$ and $\mathrm{YZ}$ is a Lewis base ( $\mathrm{Y}=$ an atom having one or more lone electron pairs). Halogen bonds are considered to be analogous to hydrogen bonds, RH $\cdots \cdot \cdot \cdot \cdot$ :YZ. The same terminology is used for both halogen bonds and hydrogen bonds. RX and RH are described as halogen-bond and hydrogen-bond donors, and the $\mathrm{YZ}$ base is the halogen-bond or hydrogen-bond acceptor. In halogen-bonded complexes the $\mathrm{X} \cdot \cdots \cdot$. Y halogen-bond distance is typically shorter than the sum of the van der Waals radii of the respective $\mathrm{X}$ and $\mathrm{Y}$ atoms. Questions have been raised 
concerning whether fluorine compounds can participate in halogen bonding. Eskandari and Lesani [69] noted that RF molecules could interact with electron donors; however, there were fundamental differences between RF $\cdots \cdots \cdot$ :YZ type interactions and the interactions generally regarded as halogen bonds. Solvation effects due to a halogen atom acting as a Lewis acid, above, will be reflected in the A value for a solute and the b-coefficient for a solvent. For the more common case of a halogen atom acting as a base, this will be reflected in the $\mathbf{B}$ value for solute and the a-coefficient for a solvent. Interactions of the type $\mathrm{AH} \cdots \cdot . \cdot \mathrm{RX}$ where the halogen atom acts as a hydrogen bond base are classified as hydrogen-bonding, as opposed to halogen-bonding, in this paper. From a mathematical standpoint it will be informative to ascertain how halogen-bond type interactions and/or halogen aromatic ring substituents might affect the other calculated equation coefficients in the Abraham model. To date we have reported Abraham model enthalpy of solvation correlations for benzene, and for three methylsubstituted benzenes (toluene, $p$-xylene and mesitylene).

\section{Experimental}

Chlorobenzene and 1,2-dichlorobenzene supplied by Sigma Aldrich (mass fraction purity min. 0.995) were used in calorimetric experiments without further purification. All organic solutes were of commercial origin (mass fraction purity more than 0.98). Before usage they were purified by repeated distillation or recrystallization in according to standards methods [70]. The content of impurities was controlled by Agilent 7890 B gas chromatograph and their mass fraction was not exceeded 0.005 after purification. Karl Fisher titration technique was used for analysis water content in studied samples. Detailed information about studied samples, their purity and water content is presented in Table 1. 
Heat effects of dissolution of organic solutes in chlorobenzene and 1,2-dichlorobenzene were measured by commercial semi-adiabatic solution calorimeter TAM III (TA-Instruments). Temperature of all dissolution experiments was kept constant at $298.15 \pm 0.01 \mathrm{~K}$. Solvent was thermostated in $100 \mathrm{~mL}$ glass cell equipped with a gold stirrer. Two different input systems were used for heat effect measurements: ampoule breaking technique for solid samples and titration technique for liquids. Calorimeter was calibrated separately for these two types of input techniques by dissolving the potassium chloride and propan-1-ol in pure water, respectively. In both cases our experimental results $\left(\Delta_{\text {soln }} H^{\mathrm{KCl} / \mathrm{H}_{2} \mathrm{O}}\right)=\left(17.41 \pm 0.04 \mathrm{~kJ} \cdot \mathrm{mol}^{-1}\right)$ and $\left(\Delta_{\text {soln }} H^{\mathrm{KCl} / \mathrm{H}_{2} \mathrm{O}}\right)=$ $\left(-10.16 \pm 0.03 \mathrm{~kJ} \cdot \mathrm{mol}^{-1}\right)$ were in good agreement with recommended literature data $\left(\Delta_{\text {soln }} H^{\mathrm{KCl} / \mathrm{H}_{2} \mathrm{O}}\right)$ $=\left(17.47 \pm 0.07 \mathrm{~kJ} \cdot \mathrm{mol}^{-1}\right)[71]$ and $\left(\Delta_{\text {soln }} H^{\mathrm{KCl} / \mathrm{H}_{2} \mathrm{O}}\right)=\left(-10.16 \pm 0.02 \mathrm{~kJ} \cdot \mathrm{mol}^{-1}\right)$ [72]. The detailed procedure of calorimetric measurements was published elsewhere [73,74]. Dissolution experiments for each solute-solvent system were reproduced at least 4 times at different concentrations of solute (see Table S1 and S2). All values of solution enthalpies were constant in studied range of concentrations. This fact confirms the assumption that each studied solute dissolves in sufficient amount of solvent to give a solution of infinite dilution.

Average values of the solution enthalpies of the organic solutes at infinite dilution in chlorobenzene and 1,2-dichlorobenzene are listed in Tables 2 and 3, respectively. Enthalpies of solution were converted to $\Delta_{\text {solv }} H^{A / S o l v e n t}$ values by subtracting the solute's measured enthalpy of vaporization (for liquid solutes) or measured enthalpy of sublimation (for solid solutions). The $\Delta_{\text {vap }} H$ and $\Delta_{\text {sub }} H$ values adjusted to $298 \mathrm{~K}$ used in the calculations came from a compilation by Acree and Chickos [75] and from Ref. [76]. Our measured $\Delta_{\text {solv }} H^{A / S o l v e n t}$ data was combined with published data taken from the chemical literature. In total we have 126 experimental $\Delta_{\text {solv }} H^{A^{/ C_{6} H_{5} C l}}$ data points for solutes dissolved in chlorobenzene (see Table 4) and 94 
experimental $\Delta_{\text {solv }} H^{A / C_{6} H_{4} C l 2}$ values for solutes dissolved in 1,2-dichlorobenzene (see Table 5). For convenience we have also tabulated in Tables 4 and 5 the numerical values of the solute descriptors for all compounds considered in the present study.

\section{Results and Discussion}

Much of the experimental enthalpic data that is available in the published literature for solutions containing either chlorobenzene or dichlorobenzene pertain to excess enthalpies for binary mixtures. Normally the enthalpic measurements are made over the entire binary composition range. There are a few data sets $[61,64,77-80]$ that we found which provide experimental measurements at sufficient low mole fraction compositions where extrapolations to infinite dilution could be made to obtain enthalpies of solution of solutes dissolved in chlorobenzene and 1,2-dichlorobenzene at 298.15 K. In Table 6 we compare our measured $\Delta_{\text {soln }} H^{\mathrm{A}_{6} \mathrm{C}_{5} \mathrm{Cl}}$ and $\Delta_{\text {soln }} H^{{\mathrm{A} / \mathrm{C}_{6} \mathrm{H}_{4} \mathrm{Cl}_{2}}_{2}}$ to values extrapolated to infinite dilution based on published excess enthalpy data. Our measured $\Delta_{\text {soln }} H^{{\mathrm{A} / \mathrm{C}_{6} \mathrm{H}_{5} \mathrm{Cl}}}$ and $\Delta_{\text {soln }} H^{{\mathrm{A} / \mathrm{C}_{6} \mathrm{H}_{4} \mathrm{Cl}_{2}}}$ data are in reasonably good agreement with the published literature values.

The chlorobenzene database is the larger of the two data sets having numerical $\Delta_{s o l v} H^{A / C 6 H 5 C l}$ values for 126 different compounds for solutes spanning a fairly wide range of descriptor values and hydrogen-bonding character. The database includes both liquid and crystalline nonelectrolyte organic compounds, as well as several inert and organic gases. Strong H-bond donors are represented in the database by 3-methoxyphenol $(\mathbf{A}=0.590)$, 4methoxyphenol $(\mathbf{A}=0.570)$, and pyrazole $(\mathbf{A}=0.540)$. Dimethyl sulfoxide $(\mathbf{B}=0.880), N, N$ dimethylformamide $(\mathbf{B}=0.800), N$-methylimidazole $(\mathbf{B}=0.800)$, trimethylamine $(\mathbf{B}=0.790)$, and tri- $n$-butylamine $(\mathbf{B}=0.790)$ are the strongest $H$-bond bases in the database. The chemical 
diversity of the solutes in Table 4 should be more than sufficient for developing meaningful Abraham model correlations having good predictive capability.

The 126 experimental $\Delta_{\text {solv }} H^{A / C_{6} H_{5} C l}$ data points in Table 4 provide two sets of 126 mathematical expressions. The first set expressions pertain to eqn. (1) and the second set of expressions pertain to eqn. (2). Each set of mathematical equations is solved simultaneously to yield the optimized numerical values of the equation coefficients, $\left(c_{h, l}, e_{h, l}, s_{h, l}, a_{h, l}, b_{h, l}\right.$, and $\left.l_{h, l}\right)$ for eqn. (1) and $\left(c_{h, v}, e_{h, v}, s_{h, v}, a_{h, v}, b_{h, v}\right.$, and $\left.l_{h, v}\right)$ for eqn. (2), that minimizes the collective differences between the experimental $\Delta_{s o l v} H^{A / C_{6} H_{5} C l}$ data and the back-calculated values based on the respective Abraham model equation. The derived Abraham model correlations:

$$
\begin{aligned}
& \Delta_{\text {solv }} H^{A / C_{6} H 5 C l}\left(\mathrm{~kJ} \mathrm{~mol}^{-1}\right)=-5.377(0.320)+5.383(0.646) \mathbf{E}-10.333(0.733) \mathbf{S}-11.478(1.005) \mathbf{A} \\
& -5.038(0.847) \mathbf{B}-9.041(0.098) \mathbf{L} \\
& \left(\text { with } \mathrm{N}=126, S D=1.52, R^{2}=0.993, F=3452\right) \\
& \Delta_{\text {solv }} H^{A / C_{6}{ }_{5} C l}\left(\mathrm{~kJ} \mathrm{~mol}^{-1}\right)=5.534(0.640)-4.164(0.984) \mathbf{E}-20.543(1.212) \mathbf{S}-16.252(1.639) \mathbf{A} \\
& -4.832(1.275) \mathbf{B}-34.675(0.615) \mathbf{V} \\
& \left(\text { with } \mathrm{N}=126, S D=2.46, R^{2}=0.982, F=1298\right)
\end{aligned}
$$

provide a very reasonable mathematical description of the measured $\Delta_{s o l v} H^{A / C_{6} H_{5} C l}$ values as evidenced by the low standard deviations of $S D=1.52 \mathrm{~kJ} \mathrm{~mol}^{-1}$ and $S D=2.46 \mathrm{~kJ} \mathrm{~mol}^{-1}$ for eqns. (1) and (2), respectively. The uncertainties in the measured enthalpies of solvation are estimated to be on the order $0.5-2 \mathrm{~kJ} \mathrm{~mol}^{-1}$ based on an error propagation analysis of the uncertainties in the enthalpy of solution data, combined with the uncertainties in the measured enthalpy of sublimation and vaporization needed to convert $\Delta_{\text {soln }} H^{A / S o l v e n t}$ to $\Delta_{\text {solv }} H^{A / S o l v e n t}$ values. Enthalpies of sublimation and vaporization for several of the nonvolatile solutes were measured at much higher temperatures and there was a fair amount of uncertainty in extrapolating the measured 
values back to $298 \mathrm{~K}$. Standard errors in the equation coefficients are given in parenthesis immediately following the calculated coefficient, and the relevant statistical information is given below the correlation equation, where $N$ is the number of experimental data points used in the regression analyses, $R^{2}$ denotes the squared correlation coefficient, and $F$ refers to the Fisher Fstatistic.

The goodness-of-fit of eqns. (3) and (4) is further documented in Figures 1 and 2. The experimental data ranges from an enthalpy of solvation of $\Delta_{\text {solv }} H^{A / C 6 H 5 C l}=10.04 \mathrm{~kJ} \mathrm{~mol}^{-1}$ for helium dissolved in chlorobenzene to $\Delta_{\text {solv }} H^{A / C_{6} \mathrm{H} 5 \mathrm{Cl}}=-78.22 \mathrm{~kJ} \mathrm{~mol}^{-1}$ for 2,6-dimethoxyphenol dissolved in chlorobenzene. Note that the back-calculated values in each figure are distributed uniformly about the diagonal line indicating a "perfect" fit. This is the first time that expressions have been reported for estimating enthalpies of solvation of solutes dissolved in chlorobenzene. Abraham and coworkers [81] have published Abraham model correlations for predicting the logarithm of the gas-to-chlorobenzene partition coefficient, $\log K$, and the logarithm of the water-to-chlorobenzene partition coefficient, $\log P$, at $298 \mathrm{~K}$. The derived $\Delta_{\text {solv }} H^{A / C_{6} H_{5} C l}$ correlations given above will expand the predictive capability of the published partition coefficients by allow researchers to extrapolate predicted $\log K$ and $\log P$ values to slightly higher and slightly lower temperatures. An error/uncertainty of $\pm 2 \mathrm{~kJ} \mathrm{~mol}^{-1}$ in the enthalpy of solvation results in an error of slightly less than $\pm 0.04 \log$ units in extrapolating a $\log K$ value measured at $298.15 \mathrm{~K}$ to a temperature of 313.15 . This level of predictive error will be sufficient for most design applications involving chemical extractions and separations.

In order to assess the predictive ability of eqns. 3 and 4 we divided the 126 data points into a training set and a test set by allowing the SPSS software to randomly select half of the experimental points. The selected data points became the training set and the compounds that were left served as the test set. Analysis of the experimental data in the training set gave 


$$
\begin{aligned}
& \Delta_{\text {solv }} H^{A / C_{6} H_{5} C l}\left(\mathrm{~kJ} \mathrm{~mol}^{-1}\right)=-5.898(0.447)+4.947(0.888) \mathbf{E}-8.438(1.019) \mathbf{S}-8.703(1.639) \mathbf{A} \\
& -6.079(1.281) \mathbf{B}-9.083(0.141) \mathbf{L} \\
& \text { (with } \mathrm{N}=63, S D=1.36, R^{2}=0.993, F=1679 \text { ) } \\
& \Delta_{\text {solv }} H^{A / C 6 H 5 C l}\left(\mathrm{~kJ} \mathrm{~mol}^{-1}\right)=4.451(0.834)-4.701(1.262) \mathbf{E}-20.777(1.463) \mathbf{S}-17.519(2.2337) \mathbf{A} \\
& -2.462(1.665) \mathbf{B}-33.914(0.749) \mathbf{V}
\end{aligned}
$$$$
\text { (with } \mathrm{N}=63, S D=2.25, R^{2}=0.984, F=711.5 \text { ) }
$$

There is very little difference in the equation coefficients for the full dataset and the training dataset correlations, thus showing that the training set of compounds is a representative sample of the total data set. Each training set equation was then used to predict the $\Delta_{\text {solv }} H^{A / C_{6} H_{5} C l}$ values for the 63 compounds in the test set. For the predicted and experimental values, we find $S D=$ $1.91 \mathrm{~kJ} \mathrm{~mol}^{-1}$ (eqn. (5)) and $S D=2.85 \mathrm{~kJ} \mathrm{~mol}^{-1}$ (eqn. (6)), $A A E$ (average absolute error) $=1.23 \mathrm{~kJ}$ $\mathrm{mol}^{-1}$ (eqn. (5)) and $A A E=1.92 \mathrm{~kJ} \mathrm{~mol}^{-1}$ (eqn. (6)), and $A E$ (average error) $=-0.27 \mathrm{~kJ} \mathrm{~mol}^{-1}$ (eqn. (5)) and $\mathrm{AE}=0.31 \mathrm{~kJ} \mathrm{~mol}^{-1}$ (eqn. (6)). There is therefore very little bias in using eqns. (5) and (6) with $A E$ equal to $-0.27 \mathrm{~kJ} \mathrm{~mol}^{-1}$ and $\mathrm{AE}=0.31 \mathrm{~kJ} \mathrm{~mol}^{-1}$, respectively. The training set and test set analyses were performed two more times with similar results. In each repetition the data set was split into new training and test sets using the SPSS randomization software. The ranges of solute descriptors covered by the respective training and test sets were approximately the same.

The Abraham model correlations for enthalpies of solvation of solutes dissolved in 1,2dichlorobenzene were derived in similar fashion by analyzing the 94 experimental $\Delta_{\text {solv }} H^{A / C_{6} H_{4} C_{2}}$ tabulated in Table 5. The derived mathematical expressions:

$$
\begin{gathered}
\Delta_{\text {solv }} H^{A / C_{6} H_{4} C l 2}\left(\mathrm{~kJ} \mathrm{~mol}^{-1}\right)=-4.609(0.714)+3.975(0.920) \mathbf{E}-8.947(0.961) \mathbf{S} \\
-8.518(1.148) \mathbf{A}-5.928(1.140) \mathbf{B}-9.182(0.186) \mathbf{L} \\
\left(\text { with } \mathrm{N}=94, S D=1.86, R^{2}=0.979, F=802.8\right)
\end{gathered}
$$




$$
\begin{gathered}
\Delta_{\text {solv }} H^{A / C_{6} H 4 C l 2}\left(\mathrm{~kJ} \mathrm{~mol}^{-1}\right)=1.234(1.047)-5.635(1.082) \mathbf{E}-16.692(1.290) \mathbf{S} \\
-12.033(1.492) \mathbf{A}-5.196(1.469) \mathbf{B}-32.033(0.845) \mathbf{V} \\
\left(\text { with } \mathrm{N}=94, S D=2.39, R^{2}=0.982, F=478.4\right)
\end{gathered}
$$

described the measured $\Delta_{\text {solv }} H^{{\mathrm{A} / \mathrm{C}_{6} \mathrm{H}_{4} C l_{2}}_{2}}$ values to within standard deviations of $1.86 \mathrm{~kJ} \mathrm{~mol}^{-1}$ and $2.39 \mathrm{~kJ} \mathrm{~mol}^{-1}$ as shown in Figures 3 and 4. The experimental values range from a value of $\Delta_{\text {solv }} H^{A / C_{6} H_{4} C l_{2}}=-23.00 \mathrm{~kJ} \mathrm{~mol}^{-1}$ for methanol to a value of $\Delta_{\text {solv }} H^{A / C_{6} H_{4} C l_{2}}=-79.54 \mathrm{~kJ} \mathrm{~mol}^{-1}$ for anthracene. As an informational note the dataset used in regression analysis contains mainly moderately volatile liquid organic solutes and nonvolatile crystalline organic solutes. There is only a single organic gas molecule, dimethylamine, in the data set. While we expect eqns. (7) and (8) to provide reasonably accurate estimations of the enthalpies of solvation of helium, hydrogen, oxygen, nitrogen and other inert gases, we would be remiss in not mentioning that such predictions would fall outside of the range of descriptor values used in deriving eqns. (7) and (8) as none of the solutes had negative L-descriptor values or really small V-descriptor values.

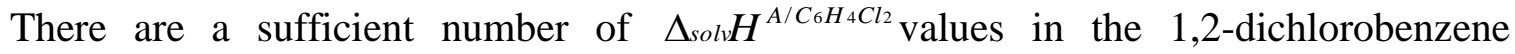
database to permit training set and test set analyses to be performed. The 94 experimental values in the large database were split into smaller training set and test sets of 47 data points each using the built-in randomization function of the SPSS software. Analysis of the 47 values in the training set gave the following two Abraham model correlations:

$$
\begin{aligned}
& \Delta_{\text {solv }} H^{A / C_{6} H_{4} C l 2}\left(\mathrm{~kJ} \mathrm{~mol}^{-1}\right)=-4.395(1.106)+3.308(1.333) \mathbf{E}-6.695(1.561) \mathbf{S}-11.700(2.260) \mathbf{A} \\
& -7.873(2.089) \mathbf{B}-9.388(0.316) \mathbf{L} \\
& \text { (with } \mathrm{N}=47, S D=1.98, R^{2}=0.979, F=382.9 \text { ) } \\
& \Delta_{s o l v} H^{A / C_{6} H_{4} C_{2}}\left(\mathrm{~kJ} \mathrm{~mol}^{-1}\right)=0.963(1.229)-3.546(1.442) \mathbf{E}-18.988(1.608) \mathbf{S}-11.848(1.877) \mathbf{A} \\
& -3.969(1.685) \mathbf{B}-32.365(0.952) \mathbf{V}
\end{aligned}
$$




$$
\text { (with } \mathrm{N}=47, S D=1.90, R^{2}=0.977, F=345.2 \text { ) }
$$

Comparison of the training set equations to eqns. (7) and (8) reveals that there is very little difference in the numerical values of the equation coefficients. The training set equations were then used to predict the enthalpies of solvation for the 47 solutes in the test sets. For the predicted and experimental values, we find $S D=2.00 \mathrm{~kJ} \mathrm{~mol}^{-1}$ (eqn. (9)) and $S D=2.96 \mathrm{~kJ} \mathrm{~mol}^{-1}$ (eqn. (10)), $A A E=1.48 \mathrm{~kJ} \mathrm{~mol}^{-1}$ (eqn. (9)) and $A A E=2.02 \mathrm{~kJ} \mathrm{~mol}^{-1}$ (eqn. (10)), and $A E=0.62 \mathrm{~kJ}$ $\mathrm{mol}^{-1}$ (eqn. (9)) and $\mathrm{AE}=-0.74 \mathrm{~kJ} \mathrm{~mol}^{-1}$ (eqn. (10)). There is therefore very little bias in using eqns. (9) and (10) with $A E$ equal to $0.62 \mathrm{~kJ} \mathrm{~mol}^{-1}$ and $\mathrm{AE}=-0.74 \mathrm{~kJ} \mathrm{~mol}^{-1}$, respectively. As before the training set and test set computations were repeated two more times with very similar results.

Each term in the Abraham model describes a different type of solute-solvent intermolecular interactions. The hydrogen bonding interactions would be given by $a_{h} \cdot \mathbf{A}+b_{h} \cdot$ B terms. In Table 5 we have compiled numerical values of the Abraham model solvent coefficients for both eqn. (1) and eqn. (2) for benzene [3], methylbenzene [4], 1,4dimethylbenzene [3], 1,3,5-trimethylbenzene [3], chlorobenzene and 1,2-dichlorobenzene. In the case of 1,4-dimethylbenzene and 1,3,5-trimethylbenzene the b coefficients were set equal to zero because the calculated numerical values were very small and the standard error in the coefficient exceeded the coefficient itself. Examination of the numerical entries in Table 7 reveals that chlorobenzene is the best $\mathrm{H}$-bond acceptor as reflected by its larger a-coefficient. Chlorobenzene interactions with acidic $\mathrm{H}$-bond donor solutes likely occur through the aromatic ring system and the lone electron pairs on the chlorine ring substituent. In the case of RX $\cdots \cdot \cdots$ :YZ halogen bonding the halogen atom (atom X) interacts with Lewis bases rather than Lewis acids. There is nothing unusual in the equation coefficients for either chlorobenzene or 1,2-dichlorobenzene to suggest strong halogen bonding. From our analysis we deduce that the interaction of halogen in 
chlorobenzene or 1,2-dichlorobenzene with basic solutes is quite small. The $b_{h} \cdot \mathbf{B}$ term in the Abraham model describes enthalpic hydrogen-bonding interactions between the solvent as a Lewis acid and basic solutes. 1,2-Dichlorobenzene having a slightly more negative $b_{h}$ coefficient is the stronger Lewis acid of the two solvents studied here. The numerical value of the $b_{\mathrm{h}} \cdot \mathbf{B}$ term (eqn. (7)) for 1,2-dichlorobenzene halogen-bonding interactions with 1-alkanols ( $\mathbf{B}=0.480)$ would be about $-2.85 \mathrm{~kJ} \mathrm{~mol}^{-1}$; for interactions with 2-alkanones $(\mathbf{B}=0.510)$ would be about $-3.02 \mathrm{~kJ} \mathrm{~mol}^{-1}$, and for interactions with alkyl alkanoates $(\mathbf{B}=0.450)$ would be about $2.67 \mathrm{~kJ} \mathrm{~mol}^{-1}$. Interactions with chlorobenzene would be slightly weaker.

In an earlier study [3] we examined the weak $\mathrm{X}-\mathrm{H} \ldots \pi(\mathrm{X}-\mathrm{O}, \mathrm{N}$, and $\mathrm{C})$ hydrogenbonding interactions between acidic solutes and alkylbenzenes (benzene, toluene, 1,4dimethylbenzene and 1,3,5-trimethylbenzene). H-bonds play an important role in understanding how different solvents affect both the reactivity and solubility of dissolved solute molecules. In accordance with the Abraham model correlations derived above, the enthalpy of hydrogen bond associated with an acidic $\mathrm{H}$-bond donor solute interacting with the $\pi$-donor site(s) or with the lone electron pairs on the chlorine atom in chlorobenzene, $\Delta_{H B} H^{A \ldots C_{6} H_{5} C l}$, would be calculated by:

$\Delta_{H B} H^{A \ldots C_{6} H_{5} C l}\left(\mathrm{~kJ} \mathrm{~mol}^{-1}\right)=-11.478 \mathbf{A}$

$\Delta_{H B} H^{A \ldots C_{6} H_{5} C l}\left(\mathrm{~kJ} \mathrm{~mol}^{-1}\right)=-16.252 \mathbf{A}$

and with the $\pi$-donor site(s) or with the lone electron pairs on the two chlorine atoms in dichlorobenzene, $\Delta_{H B} H^{A \ldots C_{6} H_{4} C l 2}$, would be calculated by:

$$
\begin{aligned}
& \Delta_{H B} H^{A \ldots C_{6} H_{4} C l_{2}}\left(\mathrm{~kJ} \mathrm{~mol}^{-1}\right)=-8.518 \mathbf{A} \\
& \Delta_{H B} H^{A \ldots C_{6} H_{4} C_{2} l_{2}}\left(\mathrm{~kJ} \mathrm{~mol}^{-1}\right)=-12.033 \mathbf{A}
\end{aligned}
$$


Data on $\triangle_{H B} H^{A \ldots C_{6} H_{5} C l}$ and $\Delta_{H B} H^{A \ldots C_{6} H_{4} C l 2}$ for several hydrogen bond acidic solutes calculated using eqns. (11) - (14) are presented in Table 8, along with corresponding enthalpy of hydrogen bond formation of the same organic substances with benzene, $\Delta_{H B} H^{A / C_{6} H_{6}}$.

Another independent method [33] for determination of hydrogen bond enthalpies based on the Solomonov et al eqn. (15) was used to verify obtained results. Previously, Solomonov et al method was used for determination of hydrogen bond enthalpies in various solute-solvent systems including different proton acceptors and proton donors [6,16,33], self-associated solvents [16-19,74], systems with weak and strong intermolecular and intramolecular hydrogen bonds $[3,76,82]$ (totally more than 500 solute-solvent systems). Values of $\Delta_{H B} H^{A \ldots S}$ obtained by this method were coincided well with the available literature data. Consequently, Solomonov et al method can be a useful tool for determination or validation of hydrogen bond enthalpies.

$$
\begin{gathered}
\Delta_{\mathrm{HB}} H^{\mathrm{A} / \mathrm{S}}=\Delta_{\text {soln }} H^{\mathrm{A} / \mathrm{S}}-\left(\delta_{\text {cav }} h^{\mathrm{S}}-\delta_{\text {cav }} h^{\mathrm{C}_{6} \mathrm{H}_{12}}\right) \cdot \mathrm{V}^{\mathrm{A}}-\Delta_{\text {soln }} H^{\mathrm{A}_{6} \mathrm{H}_{12}}-\left(a_{R}+b_{R} \cdot \sqrt{\delta_{\text {cav }} h^{\mathrm{S}}}\right) \cdot \\
\cdot\left[\left(\Delta_{\text {soln }} H^{\mathrm{A} / \mathrm{S}_{\mathrm{R}}}-\Delta_{\text {soln }} H^{{\mathrm{A} / \mathrm{C}_{6} \mathrm{H}_{12}}_{12}}\right)-\left(\delta_{\text {cav }} h^{\mathrm{S}_{\mathrm{R}}}-\delta_{\text {cav }} h^{\mathrm{C}_{6} \mathrm{H}_{12}}\right) \cdot \mathrm{V}^{\mathrm{A}}\right],
\end{gathered}
$$

Here $\Delta_{\text {soln }} H^{\mathrm{A} / \mathrm{S}}, \Delta_{\text {soln }} H^{\mathrm{A} / \mathrm{S}_{\mathrm{R}}}, \Delta_{\text {soln }} H^{\mathrm{A} / \mathrm{C}_{6} \mathrm{H}_{12}}$ are enthalpies of solution of solute $A$ in studied solvent $\mathrm{S}$, standard solvent $\mathrm{S}_{\mathrm{R}}$, and in cyclohexane, respectively; $\delta_{\text {cav }} h^{\mathrm{S}}, \delta_{\text {cav }} h^{\mathrm{S}_{\mathrm{R}}}$, and $\delta_{\text {cav }} h^{\mathrm{C}_{6} \mathrm{H}_{12}}$ are the specific relative cavity formation enthalpies for each solvent; $\mathrm{V}^{\mathrm{A}}$ is the characteristic volume of solute. Carbon tetrachloride was selected as a standard solvent $\mathrm{S}_{\mathrm{R}}$, because it does not form hydrogen bonds with any studied proton donor solutes. The specific relative cavity formation enthalpy $\delta_{\text {cav }} h^{\mathrm{S}}$ is the enthalpy of transfer of an alkane from imaginary solvent $S_{0}$, where the solution enthalpy of an alkane is zero $\left(\Delta_{\text {soln }} H^{\mathrm{C}_{\mathrm{n}} \mathrm{H}_{2 n+2} / \mathrm{s}}\right)$, to the solvent $S$, divided by the alkane's characteristic volume $\mathrm{V}^{\mathrm{C}_{\mathrm{n}} \mathrm{H}_{2 n+2}}$. Experimental data required for application of eqn. (15) were collected in Supplementary material (Table S3). 
Hydrogen bond enthalpies of proton donor solutes with chlorobenzene and 1,2dichlorobenzene determined by eqn. (15) are also presented in Table 8 . These results and values obtained using eqns. (11)-(14) are in good agreement. It proves applicability of enthalpies of solvation correlations based on the Abraham model for calculation of the energies of intermolecular hydrogen bonds in aprotic media.

\section{Conclusion}

The enthalpy of solvation correlations reported in this paper for solutes dissolved in both chlorobenzene and 1,2-dichlorobenzene at $298 \mathrm{~K}$ further illustrates the applicability of the Abraham general solvation model for describing solute transfer into condensed phases from the gas phase. The derived Abraham model correlations provide a very accurate mathematical

description of the measured $\Delta_{\text {solv }} H^{\mathrm{A} / \text { Solvent }}$ data as evidenced by standard deviations between measured and calculated values of 1.5 and $2.5 \mathrm{~kJ} \mathrm{~mol}^{-1}$ and 1.9 and $2.4 \mathrm{~kJ} \mathrm{~mol}^{-1}$ for solutes dissolved in chlorobenzene and 1,2-dichlorobenzene, respectively. Equation coefficients calculated from regression analysis of experimental $\Delta_{\text {solv }} H^{\mathrm{A} / \mathrm{Solvent}}$ data in accordance with the Abraham model are used to estimate the hydrogen-bonding interactions of proton donor solute molecules with both chlorobenzene and 1,2-dichlorobenzene. The calculated hydrogen-bonding enthalpies based on the Abraham model correlations are in good agreement with calculated values based on the Solomonov et al. method [33].

\section{Acknowledgements}

M.V., I.R. and A.Kh. gratefully acknowledge the Russian Government Program of Competitive Growth of Kazan Federal University and grant MK-7126.2015.3. 


\section{References}

[1] C. Mintz, M. Clark, K. Burton, W.E. Acree, Jr., M.H. Abraham, Enthalpy of solvation correlations for gaseous solutes dissolved in benzene and in alkane solvents based on the Abraham model. QSAR Comb. Sci. 26 (2007) 881-888.

[2] C. Mintz, K. Burton, W.E. Acree, Jr., M.H. Abraham, Enthalpy of solvation correlations for gaseous solutes dissolved in linear alkanes $\left(\mathrm{C}_{5}-\mathrm{C}_{16}\right)$ based on the Abraham model. QSAR Comb. Sci. 27 (2008) 179-186.

[3] M.A. Varfolomeev, I.T. Rakipov, W.E. Acree, Jr., M. Brumfield, M.H. Abraham, Examination of hydrogen-bond interactions between dissolved solutes and alkylbenzene solvents based on Abraham model correlations derived from measured enthalpies of solvation. Thermochim. Acta 594 (2014) 68-79.

[4] C. Mintz, M. Clark, K. Burton, W.E. Acree, Jr., M.H. Abraham, Enthalpy of solvation correlations for gaseous solutes dissolved in toluene and carbon tetrachloride based on the Abraham Model. J. Solution Chem. 36 (2007) 947-966.

[5] C. Mintz, K. Burton, W.E. Acree, Jr., M.H. Abraham, Enthalpy of solvation correlations for gaseous solutes dissolved in chloroform and 1,2-dichloroethane based on the Abraham model. Fluid Phase Equilibr. 258 (2007) 191-198.

[6] A. Wilson, A. Tian, N. Dabadge, W.E. Acree, Jr., M.A. Varfolomeev, I.T. Rakipov, S.M. Arkhipova, M.H. Abraham, Enthalpy of solvation correlations for organic solutes and gases dissolved in dichloromethane and 1,4-dioxane. Struct. Chem. 24 (2013) 18411853.

[7] T.W. Stephens, N.E. De La Rosa, M. Saifullah, S. Ye, V. Chou, A.N. Quay, W.E. Acree, Jr., M.H. Abraham, Enthalpy of solvation correlations for organic solutes and gases 
dissolved in 2-propanol, 2-butanol, 2-methyl-1-propanol and ethanol. Thermochim. Acta 523 (2011) 214-220.

[8] T.W. Stephens, V. Chou, A.N. Quay, W.E. Acree, Jr, M.H. Abraham, Enthalpy of solvation correlations for organic solutes and gases dissolved in 1-propanol and tetrahydrofuran. Thermochim. Acta 519 (2011) 103-113.

[9] C. Mintz, K. Burton, T. Ladlie, M. Clark, W.E. Acree, Jr., M.H. Abraham, Enthalpy of solvation correlations for organic solutes and gases dissolved in $\mathrm{N}, \mathrm{N}$-dimethylformamide and tert-butanol. J. Mol. Liq. 144 (2009) 23-31.

[10] C. Mintz, M. Clark, W.E. Acree, Jr., M.H. Abraham, Enthalpy of solvation correlations for gaseous solutes dissolved in water and in 1-octanol based on the Abraham model. J. Chem. Inf. Model. 47 (2007) 115-121.

[11] E. Hart, H. Zettl, D. Grover, W.E. Acree, Jr., M.H. Abraham, Abraham model enthalpy of solvation correlations for solutes dissolved in 1-alkanol solvents $\left(\mathrm{C}_{4}-\mathrm{C}_{6}\right)$. Phys. Chem. Liq. 53 (2015) 638-659.

[12] E. Hart, D. Grover, H. Zettl, W.E. Acree, Jr., M.H. Abraham, Abraham model enthalpy of solvation correlations for solutes dissolved in dimethyl carbonate and diethyl carbonate. Phys. Chem. Liq. 53 (2015) 732-747.

[13] C. Mintz, K. Burton, T. Ladlie, M. Clark, W.E. Acree, Jr., M.H. Abraham, Enthalpy of solvation correlations for gaseous solutes dissolved in dibutyl ether and ethyl acetate. Thermochim. Acta 470 (2008) 67-76.

[14] C. Mintz, J. Gibbs, W.E. Acree, Jr., M.H. Abraham, Enthalpy of solvation correlations for organic solutes and gases dissolved in acetonitrile and acetone. Thermochim. Acta 484 (2009) 65-69. 
[15] C. Mintz, K. Burton, W.E. Acree, Jr., M.H. Abraham, Enthalpy of solvation correlations for gaseous solutes dissolved in dimethyl sulfoxide and propylene carbonate based on the Abraham model. Thermochim. Acta 459 (2007) 17-25.

[16] M.A. Varfolomeev. I.T. Rakipov, B.N. Solomonov, Calorimetric investigation of hydrogen bonding of formamide and its methyl derivatives in organic solvents and water. Int. J. Thermophys. 34 (2013) 710-724.

[17] K.V. Zaitseva, M.A. Varfolomeev, V.B. Novikov, B.N. Solomonov, Enthalpy of cooperative hydrogen bonding in complexes of tertiary amines with aliphatic alcohols: Calorimetric study. J. Chem. Thermodyn. 43 (2011) 1083-1090.

[18] K.V. Zaitseva, M.A. Varfolomeev, B.N. Solomonov, Thermodynamic functions of hydrogen bonding of amines in methanol derived from solution calorimetry data and headspace analysis. Thermochimica Acta 535 (2012) 8-16.

[19] B.N. Solomonov, M.A. Varfolomeev, V.B. Novikov, A new method for the determination of cooperative hydrogen bonding enthalpy of proton acceptors with associated species of alcohols. J. Phys. Org. Chem. 19 (2006) 263-268.

[20] I.A. Sedov, M.A. Stolov, E. Hart, D. Grover, H. Zettl, V. Koshevarova, W.E. Acree, Jr., M.H. Abraham, Development of Abraham model correlations for solute transfer into 2ethoxyethanol from water and from the gas phase at 298 K. J. Mol. Liq. 208 (2015) 6370.

[21] M.H. Abraham, R.E. Smith, R. Luchtefeld, A.J. Boorem, R. Luo, W.E. Acree, Jr., Prediction of solubility of drugs and other compounds in organic solvents. J. Pharm. Sci. 99 (2010) 1500-1515. 
[22] M. Brumfield, A. Wadawadigi, N. Kuprasertkul, S. Mehta, W.E. Acree, Jr., M.H. Abraham, Abraham Model correlations for solute transfer into tributyl phosphate from both water and the gas phase. Phys. Chem. Liq. 53 (2015) 10-24.

[23] M. Brumfield, W.E. Acree, Jr., M.H. Abraham, Abraham model correlations for describing solute transfer into diisopropyl ether. Phys. Chem. Liq. 53 (2015) 25-37.

[24] D.M. Stovall, C. Dai, S. Zhang, W.E. Acree, Jr., M.H. Abraham, Abraham model correlations for describing solute transfer into anhydrous 1,2-propylene glycol for neutral and ionic species. Phys. Chem. Liq., accepted for publication.

[25] M.H. Abraham, A. Ibrahim, W.E. Acree, Jr., Air to muscle and blood/plasma to muscle distribution of volatile organic compounds and drugs: linear free energy analyses. Chem. Res. Toxicol. 19 (2006) 801-808.

[26] M.H. Abraham, A. Ibrahim, Y. Zhao, W.E. Acree, Jr., A data base for partition of volatile organic compounds and drugs from blood/plasma/serum to brain, and an LFER analysis of the data. J. Pharm. Sci. 95 (2006) 2091-2100.

[27] M.H. Abraham, A. Ibrahim, W.E. Acree, Jr., Air to liver partition coefficients for volatile organic compounds and blood to liver partition coefficients for volatile organic compounds and drugs. Eur. J. Med. Chem. 42 (2007) 743-751.

[28] M.H. Abraham, A. Ibrahim, Air to fat and blood to fat distribution of volatile organic compounds and drugs: Linear free energy analyses. Eur. J. Med. Chem. 41 (2006) 14301438.

[29] M.H. Abraham, A. Ibrahim, Blood or plasma to skin distribution of drugs: A linear free energy analysis. Int. J. Pharm. 329 (2007) 129-134. 
[30] L. Sprunger, W.E. Acree, Jr., M.H. Abraham, Linear free energy relationship correlation of the distribution of solutes between water and sodium dodecyl sulfate (sds) micelles and between gas and sds micelles. J. Chem. Inf. Model. 47 (2007) 1808-1817.

[31] L.M. Sprunger, J. Gibbs, W.E. Acree, Jr., M.H. Abraham, Linear free energy relationship correlation of the distribution of solutes between water and cetytrimethylammonium bromide (CTAB) micelles. QSAR Comb. Sci. 28 (2009) 72-88.

[32] L.M. Sprunger, J. Gibbs, W.E. Acree, Jr., M.H. Abraham, Correlation of human and animal air-to-blood partition coefficients with a single linear free energy relationship model. QSAR Comb. Sci. 27 (2008) 1130-1139.

[33] B.N. Solomonov, V.B. Novikov, M.A. Varfolomeev, N.M. Mileshko, A new method for the extraction of specific interaction enthalpy from the enthalpy of solvation, J. Phys. Org. Chem. 18 (2005) 49-61.

[34] B.N. Solomonov, V.B. Novikov, A.B. Solomonov, Multiparameter correlations for description of thermodynamic parameters of solvation: I. Enthalpy of nonspecific solvation. Russ. J. Gen. Chem. 72 (2002) 854 -863.

[35] E. Wilhelm, A. Inglese, J.-P.E. Grolier, H.V. Kehiaian, Enthalpy of mixing of chlorobenzene, 1,2-dichlorobenzene, and 1,3-dichlorobenzene with some n-alkanes. Ber. Bunsenges. Phys. Chem. 82 (1978) 384-388.

[36] M.D. Borisover, A.A. Stolov, S.V. Izosimova, F.D. Baitalov, V.A. Breus, B.N. Solomonov, Entalpija spetsificheskogo vzaimodejstvija hlor'tilenov v organicheskih rastvoriteljah. Zh. Fiz. Khim. 65 (1991) 594-599.

[37] S. Viswanathan, M.A. Rao, Y.V.L.R. Kumar, D.H.L. Prasad, Excess enthalpies of binary mixtures of methyl tert-butyl ether (MTBE) with benzene, chlorobenzene, benzonitrile, and nitrobenzene at 298.15 K. Thermochim. Acta 335 (1999) 69-72. 
[38] K.N. Surendranath, A. Krishnaian, M. Ramakrishna, Excess enthalpies of binary mixture of acetophenone with benzene and substituted benzene. Thermochim. Acta 157 (1990) 83-88.

[39] A.V. Ochkin, T.N. Vinetskaja, J. Frolov, Teplovye effekty rastvorenija tretichnyh alifaticheskih aminov v nekotoryh rastvoriteljah. Izv. Vissh. Uchebn. Zavedenij. Khimia i khim. tekhnol. 17 (1974) 677-680.

[40] R.S. Ramadevi, P. Venkatesu, M.V.P. Rao, M.R. Krishna, Excess enthalpies of binary mixtures of N,N-dimethylformamide with substituted benzenes at 298.15 K. Fluid Phase Equilibria 114 ( 1996) 189-197.

[41] J. Catalan, J. Gomez, A. Couto, J. Laynez, Toward a solvent basicity scale: the calorimetry of the pyrrole probe. J. Am. Chem. Soc. 112 (1990) 1678-1681.

[42] S. Viswanathan, M.A. Rao, D.H.L. Prasad, M.V. Rao, Excess enthalpies for anisole + benzene, + chlorobenzene, + benzonitrile, and + nitrobenzene at 298.15 K. J. Chem. Eng. Data 41 (1996) 173-174.

[43] D.D. Deshpande, M.V. Pandya, Thermodynamics of binary solutions. Part 1 - Heats of mixing of aniline in benzene, carbon tetrachloride and chlorobenzene. Trans. Faraday Soc. 61 (1965) 1858-1868.

[44] I. Uruska, H. Inerowicz, Calorimetric investigations of the solvent effect on complex formation between pyridine derivatives and molecular iodine. J. Solution Chem. 9 (1980) 97-108.

[45] J. Catalan, J. Gomez, J.L. Saiz, A. Couto, M. Ferraris, J. Laynez, Calorimetric quantification of the hydrogen-bond acidity of solvents and its relationship with solvent polarity. J. Chem. Soc. Perkin Trans.2. (1995) 2301-2305. 
[46] B.K. Hartley, H.A. Skinner, The heat of solution of iodine in some organic solvents. Trans. Faraday Soc. 46 (1950) 621-625.

[47] T.M. Letcher, U. Domanska, J. Łachwa, The excess molar enthalpies of (N-methyl-2pyrrolidinone + mono-, or di-, or trichlorobenzene) at $\mathrm{T}=298.15 \mathrm{~K}$. J. Chem. Thermodyn. 33 (2001) 1399-1404.

[48] I. Uruska, M. Koschmidder, Enthalpies of transfer of pyridines from the gas phase to solution in weakly and moderately polar aprotic solvents. J. Chem. Soc., Perkin Trans 2 (1989) 1845-1848.

[49] M.H. Abraham, Free energies, enthalpies and entropies of solution of gaseous nonpolar nonelectrolytes in water and nonaqueous solvents. The hydrophobic effect. J. Am. Chem. Soc. 104 (1982) 2085-2094.

[50] B. Ruiz, S. Otin, C. G. Losa, Excess molar enthalpies at 298.15 K of chlorobenzene +, (chloromethyl)benzene + , and (2-chloroethyl)benzene + an ether. J. Chem. Thermodyn. 16 (1984) 25-32.

[51] F. Comelli, R. Francesconi, Calorimetric study of binary mixtures containing chlorobenzene + linear and cyclic ethers. Thermochim. Acta 196 (1992) 177-180.

[52] I. Gascon, B. Giner, S. Rodríguez, C. Lafuente, F.M. Royo, Thermophysical properties of binary mixtures of 2-methyltetrahydrofuran with benzene and halobenzenes. Thermochim. Acta 439 (2005) 1-7.

[53] K. Tamura, Excess molar enthalpies and excess molar heat capacities of (2-butanone + cyclohexane, or methylcyclohexane, or benzene, or toluene, or chlorobenzene, or cyclohexanone) at $\mathrm{T}=298.15 \mathrm{~K} . \mathrm{J}$. Chem. Thermodyn. 33 (2001) 1345-1353.

[54] T. Kimura, T. Tsuda, S. Takagi, Excess enthalpies of some halogenized aromatic compounds + methyl methylthiomethyl sulfoxide or dimethyl sulfoxide at $298.15 \mathrm{~K}$. XI. 
Thermodynamics of liquid mixtures containing methyl methylthiomethyl sulfoxide. Thermochim. Acta 267 (1995) 333-342.

[55] R. Tanaka, G. C. Benson, Excess molar enthalpies and volumes for mixtures of chlorobenzene with some aromatic hydrocarbons at 298.15 K. J. Chem. Eng. Data 21 (1976) 320-324.

[56] I. Nagata, K. Tamura, Excess molar enthalpies of chlorobenzene + methanol, + acetonitrile, and + ethanol and of (acetonitrile + chlorobenzene) + methanol and + ethanol at 298.15 K. J. Chem. Thermodyn. 18 (1986) 39-44.

[57] I. Nagata, K. Tamura, Excess molar enthalpies of (propan-1-ol or propan-2-ol + acetonitrile), (propan-1-ol or propan-2-ol + chlorobenzene), and (propan-1-ol or propan2-ol + acetonitrile + chlorobenzene) at 298.15 K. J. Chem. Thermodyn. 20 (1988) 87-93.

[58] S. Freire, L. Segade, S. Garcia-Garabal, J. Jiménez de Llano, M. Domínguez, E. Jiménez, The ternary system propyl propanoate + hexane + chlorobenzene at $298.15 \mathrm{~K}$. Excess molar enthalpies. J. Therm. Anal. Calorim. 70 (2002) 243-250.

[59] I. Short, A. Sahgal, W. Hayduk, Solubility of ammonia and hydrogen sulfide in several polar solvents. J. Chem. Eng. Data 28 (1983) 63-66.

[60] S. Otin, M. J. Toledo, J. Munoz, I. Velasco, C. G. Losa, Excess molar enthalpies of (a halogenobenzene + benzene or + toluene) and of some (a dihalogenobenzene + benzene) J. Chem. Thermodyn. 17 (1985) 935-940.

[61] M.M. Mato, J. Balseiro, J. Salgado, E. Jimenez, J.L. Legido, M.M. Pineiro, M.I.P. Andrade, Study on excess molar enthalpies and excess molar volumes of the binary systems 1,2-dichlorobenzene + benzene, hexane, 1-chlorohexane) and 1,3dichlorobenzene + (benzene, hexane, 1-chlorohexane) at 298.15 K. J. Chem. Eng. Data 47 (2002) 4-7. 
[62] R.S. Drago, M.S. Nozari, G.C. Vogel, A procedure for eliminating and evaluating solvent effect on thermodynamic data for donor-acceptor interactions J. Am. Chem. Soc. 94 (1972) 90-94.

[63] E.M. Arnett, E. Mitchell, T.S.S. R. Murty, "Basicity". A comparison of hydrogen bonding and proton transfer to some Lewis bases. J. Am. Chem. Soc. 96 (1974) 38753891.

[64] A. Tanaka, G.C. Benson, Excess enthalpies and volumes for binary mixtures of some chlorobenzenes at 298.15 K. J. Chem. Eng. Data 24 (1979) 37-39.

[65] V.R. Venkatachaliah, R. Radhakrishnan, S.R. Pamulaparti, Solubility of dimethylamine in o-dichlorobenzene under isoproturon synthesis conditions. J. Chem. Eng. Data 38 (1993) 245-246.

[66] O. Dumele, D. Wu, N. Trapp, N. Goroff, F. Diederich, Halogen bonding of (iodoethylnyl)benzene derivatives in solution. Org. Lett. 16 (2014) 4722-4725.

[67] A.V. Jentzsch, Applications of halogen bonding in solution. Pure Appl. Chem. 87 (2015) $15-41$

[68] H. Toril, M. Yoshida, Properties of halogen atoms for representing electrostatic interactions related to halogen bonding and their substituent effects. J. Comput. Chem. 31 (2010) 107-116.

[69] K. Eskandari, M. Lesani, Does fluorine participate in halogen bonding? Chem. Eur. J. 21 (2015) 4739-4746.

[70] D.D. Perrin, W.L.F. Armarego, D.R. Perrin, Purification of Laboratory Chemicals, 2nd ed., Pergamon Press, Oxford, 1980. 
[71] R. Sabbah, X.W. An, J.S. Chickos, M.L.P. Leitao, M.V. Roux, L.A. Torres, Reference materials for calorimetry and differential thermal analysis. Thermochim. Acta 131 (1999) 9-204.

[72] I. Wadso, R.N. Goldberg, Standards in isothermal microcalorimetry (IUPAC Technical Report). Pure Appl. Chem. 73 (2001) 1625-1639.

[73] M.A. Varfolomeev, A.A. Khachatrian, B.S. Akhmadeev, B.N. Solomonov, A.V. Yermalayeu, S.P. Verevkin, Enthalpies of solution and enthalpies of solvation in water: the anion effect in ionic liquids with common 1-ethyl-3-methyl-imidazolium cation. J. Solution Chem. 44 (2015) 811-823.

[74] K.V. Zaitseva, M.A. Varfolomeev, B.N. Solomonov, Thermodynamics of hydrogen bonding of weak bases in alcohol solutions: calorimetry of solution, IR-spectroscopy and vapor pressure analysis. J. Mol. Struct. 1018 (2012) 14-20.

[75] W.E. Acree Jr., J.S. Chickos, Phase transition enthalpy measurements of organic and organometallic compounds. Sublimation, vaporization and fusion enthalpies from 1880 to 2010. J. Phys. Chem. Ref. Data 39 (2010) 043101/1-043101/942.

[76] M.A. Varfolomeev, D.I. Abaidullina, B.N. Solomonov, S.P. Verevkin, V.N. Emel'yanenko, Pairwise substitution effects, inter and intramolecular hydrogen bond in methoxyphenols and dimethoxybenzenes. Thermochemistry, calorimetry and first principles calculations. J. Phys. Chem. B 114 (2010) 16503-16516.

[77] J.P. Chao, M. Dai, Studies on thermodynamic properties of binary mixtures containing an alcohol. XI. Excess enthalpies of each (one of the four butanols + chlorobenzene or aniline). J. Chem. Thermodyn. 21 (1989) 337-342.

[78] Y.X. Wang, J.P. Chao, M. Dai, Studies on the thermodynamic properties of binary mixtures containing an alcohol. XIII. Excess molar enthalpies of some mixtures of n- 
alcohols with aniline or chlorobenzene at $298.15 \mathrm{~K}$. Thermochim. Acta 169 (1990) 161 169.

[79] R. Tanaka, S. Murakami, R. Fujishiro, Excess enthalpies of mixing of a polar liquid + a nonpolar liquid at 298.15 K. J. Chem. Thermodyn. 6 (1974) 209-218.

[80] R. Tanaka, G.C. Benson, Excess enthalpies and volumes for mixtures of odichlorobenzene with some aromatic hydrocarbons at 298.15 K. J. Chem. Eng. Data 22 (1977) 291-294.

[81] M.H. Abraham, W.E. Acree, Jr., A.J. Leo, D. Hoekman, Partition of compounds from water and from air into the wet and dry monohalobenzenes. New J. Chem. 33 (2009) 1685-1692.

[82] V.B. Novikov, D.I. Abaidullina, N.Z. Gainutdinova, M.A. Varfalomeev, B.N. Solomonov, Calorimetric determination of the enthalpy of specific interaction of chloroform with a number of proton-acceptor compounds. Russ. J. Phys. Chem. 80 (2006) 1790-1794. 
Table 1. Characteristics of the chemicals studied in this work

2

\begin{tabular}{|c|c|c|c|c|c|c|}
\hline $\begin{array}{l}\text { Chemical } \\
\text { Name }\end{array}$ & Source & $\begin{array}{c}\text { Initial Mass } \\
\text { Fraction Purity }\end{array}$ & $\begin{array}{l}\text { Purification } \\
\text { Method }\end{array}$ & $\begin{array}{c}\text { Final Mass } \\
\text { Fraction Purity }\end{array}$ & $\begin{array}{l}\text { Analysis } \\
\text { Method }\end{array}$ & $\begin{array}{c}\text { Mass fraction of } \\
\text { Water }\end{array}$ \\
\hline Acetonitrile (I) & Sigma Aldrich & 0.99 & Distillation & 0.998 & $\mathrm{GC}$ & 0.0002 \\
\hline Acetone (I) & Sigma Aldrich & 0.99 & Distillation & 0.997 & $\mathrm{GC}$ & 0.0002 \\
\hline Acetophenone (I) & Sigma Aldrich & 0.98 & Distillation & 0.996 & $\mathrm{GC}$ & 0.0005 \\
\hline Anisole (I) & Sigma Aldrich & 0.98 & Distillation & 0.996 & $\mathrm{GC}$ & 0.0003 \\
\hline Aniline (I) & Sigma Aldrich & 0.99 & Distillation & 0.998 & $\mathrm{GC}$ & 0.0003 \\
\hline Anthracene (cr) & Sigma Aldrich & 0.99 & None & - & - & - \\
\hline Benzonitrile (I) & Sigma Aldrich & 0.98 & Distillation & 0.999 & GC & 0.0002 \\
\hline Benzophenone (cr) & Sigma Aldrich & 0.99 & None & - & - & - \\
\hline Biphenyl (cr) & Sigma Aldrich & 0.99 & None & - & - & - \\
\hline Bromobenzene (I) & Sigma Aldrich & 0.98 & Distillation & 0.996 & $\mathrm{GC}$ & 0.0003 \\
\hline Butanone (I) & Sigma Aldrich & 0.98 & Distillation & 0.996 & $\mathrm{GC}$ & 0.0002 \\
\hline Butan-1-ol (I) & Sigma Aldrich & 0.99 & Distillation & 0.997 & $\mathrm{GC}$ & 0.0004 \\
\hline Butyl acetate (I) & Sigma Aldrich & 0.98 & Distillation & 0.998 & $\mathrm{GC}$ & 0.0003 \\
\hline Butyl benzoate (I) & Sigma Aldrich & 0.99 & Distillation & 0.996 & $\mathrm{GC}$ & 0.0002 \\
\hline Butyronitrile (I) & Sigma Aldrich & 0.98 & Distillation & 0.997 & $\mathrm{GC}$ & 0.0002 \\
\hline Chlorobenzene (I) & Sigma Aldrich & $\geq 0.995$ & None & - & - & - \\
\hline
\end{tabular}




\begin{tabular}{|c|c|c|c|c|c|c|}
\hline 1-Chlorobutane (I) & Sigma Aldrich & 0.98 & Distillation & 0.995 & GC & 0.0004 \\
\hline 2-Chlorophenol (I) & Sigma Aldrich & 0.98 & Distillation & 0.996 & GC & 0.0002 \\
\hline$n$-Decane (I) & Sigma Aldrich & 0.99 & None & - & - & - \\
\hline Decan-1-ol (I) & Sigma Aldrich & 0.98 & Distillation & 0.995 & GC & 0.0004 \\
\hline Di-n-butyl ether (I) & Sigma Aldrich & 0.98 & Distillation & 0.996 & GC & 0.0001 \\
\hline 1,2-Dichlorobenzene (I) & Sigma Aldrich & $\geq 0.995$ & None & - & - & - \\
\hline 1,2-Dichloropropane (I) & Sigma Aldrich & 0.98 & Distillation & 0.995 & GC & 0.0003 \\
\hline 1,4-Dioxane (I) & Sigma Aldrich & 0.98 & Distillation & 0.995 & $\mathrm{GC}$ & 0.0003 \\
\hline$n$-Dodecane (I) & Sigma Aldrich & 0.99 & None & - & - & - \\
\hline Dichloromethane (I) & Sigma Aldrich & 0.99 & Distillation & 0.996 & GC & 0.0002 \\
\hline Diethyl ether (I) & Ekos & 0.98 & Distillation & 0.997 & GC & 0.0001 \\
\hline 2,6-Dimethoxyphenol (cr) & Sigma Aldrich & 0.97 & Sublimation & 0.998 & GC & 0.0004 \\
\hline $\mathrm{N}, \mathrm{N}$-Dimethylacetamide (I) & Sigma Aldrich & 0.98 & Distillation & 0.997 & GC & 0.0002 \\
\hline $\mathrm{N}, \mathrm{N}$-Dimethylformamide (I) & Sigma Aldrich & 0.98 & Distillation & 0.997 & GC & 0.0002 \\
\hline Ethanol (I) & Sigma Aldrich & 0.98 & Distillation & 0996 & GC & 0.0004 \\
\hline Ethyl acetate (I) & Sigma Aldrich & 0.99 & None & - & - & - \\
\hline Ethyl benzoate (I) & Sigma Aldrich & 0.98 & Distillation & 0.995 & GC & 0.0002 \\
\hline Ethyl salicylate (I) & Sigma Aldrich & 0.98 & Distillation & 0.996 & $\mathrm{GC}$ & 0.0003 \\
\hline Fluorobenzene (I) & Sigma Aldrich & 0.99 & Distillation & 0.998 & GC & 0.0002 \\
\hline n-Heptane (I) & Sigma Aldrich & 0.99 & None & - & - & - \\
\hline
\end{tabular}




\begin{tabular}{|c|c|c|c|c|c|c|}
\hline Heptan-2-one (I) & Sigma Aldrich & 0.98 & Distillation & 0.997 & GC & 0.0002 \\
\hline n-Hexane (I) & Sigma Aldrich & 0.99 & None & - & - & - \\
\hline Hexan-1-ol (I) & Sigma Aldrich & 0.98 & Distillation & 0.997 & GC & 0.0003 \\
\hline 2-Hydroxyacetophenone (I) & Sigma Aldrich & 0.98 & Distillation & 0.996 & $\mathrm{GC}$ & 0.0003 \\
\hline Indole (cr) & Sigma Aldrich & 0.98 & Sublimation & 0.998 & $\mathrm{GC}$ & 0.0004 \\
\hline Methanol (I) & Sigma Aldrich & 0.98 & Distillation & 0.998 & $\mathrm{GC}$ & 0.0004 \\
\hline 2-Methoxyphenol (I) & Sigma Aldrich & 0.98 & Distillation & 0.997 & GC & 0.0002 \\
\hline 3-Methoxyphenol (I) & Sigma Aldrich & 0.97 & Distillation & 0.997 & $\mathrm{GC}$ & 0.0002 \\
\hline 4-Methoxyphenol (cr) & Sigma Aldrich & 0.97 & Recrystallization & 0.995 & GC & 0.0004 \\
\hline Methyl acetate (I) & Sigma Aldrich & 0.99 & None & - & - & - \\
\hline Methyl benzoate (I) & Sigma Aldrich & 0.98 & Distillation & 0.998 & $\mathrm{GC}$ & 0.0002 \\
\hline Mesitylene (I) & Sigma Aldrich & 0.97 & Distillation & 0.997 & $\mathrm{GC}$ & 0.0002 \\
\hline Methyl propionate (I) & Sigma Aldrich & 0.99 & Distillation & 0.997 & $\mathrm{GC}$ & 0.0002 \\
\hline Methyl salicylate (I) & Sigma Aldrich & 0.98 & Distillation & 0.997 & GC & 0.0002 \\
\hline Naphthalene (cr) & Sigma Aldrich & 0.98 & Recrystallization & 0.996 & GC & 0.0005 \\
\hline n-Nonane (I) & Sigma Aldrich & 0.99 & None & - & - & - \\
\hline Nonan-2-one (I) & Sigma Aldrich & 0.98 & Distillation & 0.998 & $\mathrm{GC}$ & 0.0002 \\
\hline n-Octane (I) & Sigma Aldrich & 0.99 & None & - & - & - \\
\hline Octan-1-ol (I) & Sigma Aldrich & 0.98 & Distillation & 0.998 & GC & 0.0003 \\
\hline Octan-2-one (I) & Sigma Aldrich & 0.98 & Distillation & 0.998 & GC & 0.0002 \\
\hline
\end{tabular}




\begin{tabular}{|c|c|c|c|c|c|c|}
\hline Pentan-2-one (I) & Sigma Aldrich & 0.98 & Distillation & 0.998 & $\mathrm{GC}$ & 0.0002 \\
\hline Pentan-1-ol (I) & Sigma Aldrich & 0.98 & Distillation & 0.998 & $\mathrm{GC}$ & 0.0004 \\
\hline 2-Picoline (I) & Sigma Aldrich & 0.98 & Distillation & 0.998 & $\mathrm{GC}$ & 0.0002 \\
\hline 3-Picoline (I) & Sigma Aldrich & 0.98 & Distillation & 0.997 & $\mathrm{GC}$ & 0.0002 \\
\hline 4-Picoline (I) & Sigma Aldrich & 0.98 & Distillation & 0.998 & $\mathrm{GC}$ & 0.0002 \\
\hline Propan-1-ol (I) & Sigma Aldrich & 0.98 & Distillation & 0.998 & $\mathrm{GC}$ & 0.0004 \\
\hline Propionitrile (I) & Sigma Aldrich & 0.98 & Distillation & 0.998 & $\mathrm{GC}$ & 0.0002 \\
\hline Propyl acetate (I) & Sigma Aldrich & 0.98 & Distillation & 0.999 & $\mathrm{GC}$ & 0.0002 \\
\hline Propyl benzoate (I) & Sigma Aldrich & 0.97 & Distillation & 0.999 & $\mathrm{GC}$ & 0.0002 \\
\hline Pyrazole (cr) & Sigma Aldrich & 0.98 & Sublimation & 0.998 & $\mathrm{GC}$ & 0.0004 \\
\hline Pyridine (I) & Sigma Aldrich & 0.98 & Distillation & 0.998 & $\mathrm{GC}$ & 0.0002 \\
\hline Tetrachloromethane (I) & Ekos & $\geq 0.995$ & None & - & $=$ & 0.0001 \\
\hline Tetrahydrofuran (I) & Sigma Aldrich & 0.98 & Distillation & 0.998 & $\mathrm{GC}$ & 0.0002 \\
\hline Tri- $n$-butylamine (I) & Sigma Aldrich & 0.98 & Distillation & 0.998 & $\mathrm{GC}$ & 0.0002 \\
\hline Trichloromethane (I) & Sigma Aldrich & 0.98 & Distillation & 0.999 & $\mathrm{GC}$ & 0.0002 \\
\hline o-Xylene (I) & Sigma Aldrich & 0.99 & Distillation & 0.998 & $\mathrm{GC}$ & 0.0002 \\
\hline m-Xylene (I) & Sigma Aldrich & 0.98 & Distillation & 0.998 & $\mathrm{GC}$ & 0.0002 \\
\hline p-Xylene (I) & Sigma Aldrich & 0.99 & Distillation & 0.998 & GC & 0.0002 \\
\hline
\end{tabular}


5 Table 2. Enthalpies of solution $\left(\mathrm{kJ} \cdot \mathrm{mol}^{-1}\right)$ at infinite dilution of different

6 organic solutes in chlorobenzene, measured in this work at $298.15 \pm 0.01 \mathrm{~K}$

7 and $0.1 \mathrm{MPa} .^{\mathrm{a}}$

8

\begin{tabular}{|c|c|c|}
\hline $\mathrm{N}$ & Solute & $\Delta_{\text {soln }} H^{\mathrm{A} / \mathrm{C}_{6} \mathrm{H}_{5} \mathrm{Cl}}$ \\
\hline 1 & Acetone (1) & $-0.01 \pm 0.004^{b}$ \\
\hline 2 & Benzonitrile (1) & $0.52 \pm 0.04$ \\
\hline 3 & Butyl acetate (1) & $-1.61 \pm 0.04$ \\
\hline 4 & Butan-1-ol (1) & $15.87 \pm 0.05$ \\
\hline 5 & Butyl benzoate (1) & $-0.64 \pm 0.02$ \\
\hline 6 & Butyronitrile (1) & $0.08 \pm 0.01$ \\
\hline 7 & 2-Chlorophenol (1) & $-4.84 \pm 0.07$ \\
\hline 8 & $n$-Decane (1) & $3.62 \pm 0.04$ \\
\hline 9 & Decan-1-ol (1) & $15.27 \pm 0.10$ \\
\hline 10 & Dichloromethane (1) & $0.32 \pm 0.01$ \\
\hline 11 & $N, N$-Dimethylacetamide (l) & $-2.55 \pm 0.02$ \\
\hline 12 & 2,6-Dimethoxyphenol (cr) & $20.18 \pm 0.11$ \\
\hline 13 & $n$-Dodecane (1) & $4.27 \pm 0.04$ \\
\hline 14 & Ethyl acetate (1) & $-0.78 \pm 0.01$ \\
\hline 15 & Ethyl benzoate (1) & $-0.44 \pm 0.02$ \\
\hline 16 & Ethyl salicylate (I) & $0.09 \pm 0.02$ \\
\hline 17 & n-Heptane (l) & $2.77 \pm 0.03$ \\
\hline 18 & Heptan-2-one (1) & $-1.64 \pm 0.02$ \\
\hline 19 & Hexan-1-ol (1) & $15.19 \pm 0.14$ \\
\hline 20 & Indole (cr) & $13.62 \pm 0.42$ \\
\hline 21 & Mesitylene (1) & $-0.09 \pm 0.02$ \\
\hline 22 & 2-Methoxyphenol (1) & $4.69 \pm 0.03$ \\
\hline 23 & 3-Methoxyphenol (1) & $6.95 \pm 0.12$ \\
\hline
\end{tabular}




\begin{tabular}{|c|c|c|}
\hline 24 & 4-Methoxyphenol (cr) & $26.43 \pm 0.11$ \\
\hline 25 & Methyl acetate (1) & $0.16 \pm 0.02$ \\
\hline 26 & Methyl benzoate (1) & $0.09 \pm 0.01$ \\
\hline 27 & Methyl propionate (1) & $-0.34 \pm 0.02$ \\
\hline 28 & Methyl salicylate (1) & $1.03 \pm 0.06$ \\
\hline 29 & $n$-Nonane (1) & $3.39 \pm 0.02$ \\
\hline 30 & Nonan-2-one (1) & $-1.43 \pm 0.02$ \\
\hline 31 & $n$-Octane (1) & $3.08 \pm 0.01$ \\
\hline 32 & Octan-2-one (1) & $-1.43 \pm 0.02$ \\
\hline 33 & Octan-1-ol (1) & $15.11 \pm 0.18$ \\
\hline 34 & Pentan-1-ol (1) & $15.22 \pm 0.05$ \\
\hline 35 & Pentan-2-one (1) & $-1.24 \pm 0.02$ \\
\hline 36 & 3-Picoline (1) & $-0.39 \pm 0.01$ \\
\hline 37 & 4-Picoline (1) & $0.06 \pm 0.01$ \\
\hline 38 & Propionitrile (1) & $0.73 \pm 0.01$ \\
\hline 39 & Propyl acetate (1) & $-1.25 \pm 0.02$ \\
\hline 40 & Propyl benzoate (1) & $-0.66 \pm 0.01$ \\
\hline 41 & Pyrazole (cr) & $26.60 \pm 0.06$ \\
\hline 42 & Tetrachloromethane (1) & $-0.25 \pm 0.02$ \\
\hline 43 & Trichloromethane (1) & $-0.60 \pm 0.01$ \\
\hline
\end{tabular}

$9 \quad{ }^{a}$ Standard uncertainties $u$ are $u(\mathrm{~T})=0.01 \mathrm{~K}, u(\mathrm{p})=10 \mathrm{kPa}$.

$10{ }^{\mathrm{b}}$ Uncertainties of solution enthalpies are calculated as an experimental standard deviation.

11

12 
14 Table 3. Enthalpies of solution $\left(\mathrm{kJ} \cdot \mathrm{mol}^{-1}\right)$ at infinite dilution of different 15 organic solutes in 1,2-dichlorobenzene, measured in this work at 298.15 \pm 0.01 $16 \mathrm{~K}$ and $0.1 \mathrm{MPa} .^{\mathrm{a}}$

17

\begin{tabular}{|c|c|c|}
\hline $\mathrm{N}$ & Solute & $\Delta_{\text {soln }} H^{\mathrm{A}^{/ C_{6}} \mathrm{H}_{4} \mathrm{Cl}_{2}}$ \\
\hline 1 & Acetonitrile (l) & $3.23 \pm 0.03^{b}$ \\
\hline 2 & Acetone (1) & $0.55 \pm 0.01$ \\
\hline 3 & Acetophenone (1) & $0.78 \pm 0.02$ \\
\hline 4 & Anisole (1) & $0.42 \pm 0.03$ \\
\hline 5 & Aniline (l) & $2.51 \pm 0.02$ \\
\hline 6 & Anthracene (cr) & $22.37 \pm 0.14$ \\
\hline 7 & Benzonitrile (l) & $0.62 \pm 0.02$ \\
\hline 8 & Benzophenone (cr) & $16.73 \pm 0.05$ \\
\hline 9 & Biphenyl (cr) & $16.17 \pm 0.27$ \\
\hline 10 & Bromobenzene (l) & $0.33 \pm 0.01$ \\
\hline 11 & Butanone (l) & $-0.46 \pm 0.02$ \\
\hline 12 & Butan-1-ol (1) & $15.86 \pm 0.06$ \\
\hline 13 & Butyl acetate (1) & $-1.00 \pm 0.05$ \\
\hline 14 & Butyl benzoate (1) & $-0.71 \pm 0.02$ \\
\hline 15 & Butyronitrile (l) & $0.82 \pm 0.01$ \\
\hline 16 & Chlorobenzene (l) & $0.26 \pm 0.03$ \\
\hline 17 & 1-Chlorobutane (1) & $0.10 \pm 0.01$ \\
\hline 18 & 2-Chlorophenol (l) & $-3.21 \pm 0.03$ \\
\hline 19 & $n$-Decane (1) & $3.50 \pm 0.03$ \\
\hline 20 & Decan-1-ol (1) & $15.60 \pm 0.06$ \\
\hline 21 & Di-n-butyl ether (l) & $-0.10 \pm 0.02$ \\
\hline 22 & 1,2-Dichloropropane (l) & $1.16 \pm 0.03$ \\
\hline 23 & 1,4-Dioxane (l) & $-0.80 \pm 0.03$ \\
\hline 24 & $n$-Dodecane (1) & $3.98 \pm 0.04$ \\
\hline
\end{tabular}




\begin{tabular}{|c|c|c|}
\hline 25 & Dichloromethane (1) & $0.95 \pm 0.01$ \\
\hline 26 & Diethyl ether (1) & $0.92 \pm 0.01$ \\
\hline 27 & 2,6-Dimethoxyphenol (cr) & $20.65 \pm 0.10$ \\
\hline 28 & $N, N$-Dimethylacetamide (l) & $-2.21 \pm 0.06$ \\
\hline 29 & $N, N$-Dimethylformamide (l) & $-0.37 \pm 0.01$ \\
\hline 30 & Ethanol (1) & $15.96 \pm 0.02$ \\
\hline 31 & Ethyl acetate (1) & $-0.30 \pm 0.03$ \\
\hline 32 & Ethyl benzoate (1) & $-0.28 \pm 0.02$ \\
\hline 33 & Ethyl salicylate (1) & $0.10 \pm 0.03$ \\
\hline 34 & Fluorobenzene (1) & $0.69 \pm 0.02$ \\
\hline 35 & $n$-Heptane (1) & $2.83 \pm 0.03$ \\
\hline 36 & Heptan-2-one (1) & $-1.31 \pm 0.02$ \\
\hline 37 & $n$-Hexane (1) & $2.64 \pm 0.03$ \\
\hline 38 & Hexan-1-ol (1) & $15.40 \pm 0.17$ \\
\hline 39 & 2-Hydroxyacetophenone (1) & $0.88 \pm 0.05$ \\
\hline 40 & Indole (cr) & $12.52 \pm 0.08$ \\
\hline 41 & Methanol (1) & $15.00 \pm 0.02$ \\
\hline 42 & 2-Methoxyphenol (1) & $4.53 \pm 0.02$ \\
\hline 43 & 3-Methoxyphenol (1) & $9.14 \pm 0.08$ \\
\hline 44 & 4-Methoxyphenol (cr) & $27.43 \pm 0.26$ \\
\hline 45 & Methyl acetate (1) & $0.46 \pm 0.02$ \\
\hline 46 & Methyl benzoate (1) & $0.15 \pm 0.01$ \\
\hline 47 & Mesitylene (1) & $-0.22 \pm 0.02$ \\
\hline 48 & Methyl propionate (1) & $-0.39 \pm 0.02$ \\
\hline 49 & Methyl salicylate (1) & $0.65 \pm 0.02$ \\
\hline 50 & Naphthalene (cr) & $17.35 \pm 0.10$ \\
\hline 51 & $n$-Nonane (1) & $3.27 \pm 0.02$ \\
\hline 52 & Nonan-2-one (1) & $-1.32 \pm 0.05$ \\
\hline 53 & n-Octane (1) & $3.00 \pm 0.02$ \\
\hline
\end{tabular}




\begin{tabular}{|c|c|c|}
\hline 54 & Octan-1-ol (1) & $15.47 \pm 0.03$ \\
\hline 55 & Octan-2-one (1) & $-1.30 \pm 0.03$ \\
\hline 56 & Pentan-2-one (1) & $-0.92 \pm 0.02$ \\
\hline 57 & Pentan-1-ol (1) & $15.31 \pm 0.09$ \\
\hline 58 & 2-Picoline (1) & $1.11 \pm 0.05$ \\
\hline 59 & 3-Picoline (1) & $1.05 \pm 0.04$ \\
\hline 60 & 4-Picoline (1) & $1.53 \pm 0.04$ \\
\hline 61 & Propan-1-ol (1) & $15.96 \pm 0.09$ \\
\hline 62 & Propionitrile (1) & $1.56 \pm 0.01$ \\
\hline 63 & Propyl acetate (1) & $-0.76 \pm 0.05$ \\
\hline 64 & Propyl benzoate (1) & $-0.52 \pm 0.02$ \\
\hline 65 & Pyrazole (cr) & $24.39 \pm 0.03$ \\
\hline 66 & Pyridine (1) & $1.62 \pm 0.01$ \\
\hline 67 & Tetrahydrofuran (1) & $-0.91 \pm 0.01$ \\
\hline 68 & Tri- $n$-butylamine (1) & $2.17 \pm 0.03$ \\
\hline 69 & Trichloromethane (1) & $0.05 \pm 0.02$ \\
\hline 70 & $o$-Xylene (1) & $-0.34 \pm 0.01$ \\
\hline 71 & $m$-Xylene (l) & $-0.27 \pm 0.03$ \\
\hline 72 & p-Xylene (1) & $-0.29 \pm 0.01$ \\
\hline
\end{tabular}

$18{ }^{a}$ Standard uncertainties $u$ are $u(\mathrm{~T})=0.01 \mathrm{~K}, u(\mathrm{p})=10 \mathrm{kPa}$.

$19{ }^{\mathrm{b}}$ Uncertainties of solution enthalpies are calculated as an experimental standard deviation. 
23 Table 4. Values of the gas to chlorobenzene solvation enthalpies in $\mathrm{kJ} \cdot \mathrm{mol}^{-1}$ at $298 \mathrm{~K}$,

$24 \Delta_{\text {solv }} H^{A / C_{6} H_{5} C l}$, for 126 solutes together with the solute descriptors

25

\begin{tabular}{|c|c|c|c|c|c|c|c|c|}
\hline Solute (A) & $\mathbf{E}$ & $\mathbf{S}$ & $\mathbf{A}$ & B & $\mathbf{L}$ & $\mathbf{V}$ & $\Delta_{\text {solv }} H^{A / C_{6} H_{5} C l}$ & Ref \\
\hline Helium & 0.000 & 0.000 & 0.000 & 0.000 & -1.741 & 0.0680 & 10.04 & 49 \\
\hline Neon & 0.000 & 0.000 & 0.000 & 0.000 & -1.575 & 0.0850 & 9.62 & 49 \\
\hline Argon & 0.000 & 0.000 & 0.000 & 0.000 & -0.688 & 0.1900 & 0.46 & 49 \\
\hline Krypton & 0.000 & 0.000 & 0.000 & 0.000 & -0.211 & 0.2460 & -3.05 & 49 \\
\hline Xenon & 0.000 & 0.000 & 0.000 & 0.000 & 0.378 & 0.3290 & -8.70 & 49 \\
\hline Hydrogen & 0.000 & 0.000 & 0.000 & 0.000 & -1.200 & 0.1086 & 4.98 & 49 \\
\hline Nitrogen & 0.000 & 0.000 & 0.000 & 0.000 & -0.978 & 0.2222 & 2.42 & 49 \\
\hline Oxygen & 0.000 & 0.000 & 0.000 & 0.000 & -0.723 & 0.1830 & 0.63 & 49 \\
\hline Carbon monoxide & 0.000 & 0.000 & 0.000 & 0.000 & -0.836 & 0.2220 & 0.96 & 49 \\
\hline Methane & 0.000 & 0.000 & 0.000 & 0.000 & -0.323 & 0.2495 & -2.56 & 49 \\
\hline Ethane & 0.000 & 0.000 & 0.000 & 0.000 & 0.492 & 0.3904 & -9.87 & 49 \\
\hline Propane & 0.000 & 0.000 & 0.000 & 0.000 & 1.050 & 0.5313 & -15.77 & 49 \\
\hline$n$-Hexane & 0.000 & 0.000 & 0.000 & 0.000 & 2.668 & 0.9540 & -29.04 & 49 \\
\hline$n$-Heptane & 0.000 & 0.000 & 0.000 & 0.000 & 3.173 & 1.0949 & -33.83 & This work \\
\hline$n$-Octane & 0.000 & 0.000 & 0.000 & 0.000 & 3.677 & 1.2358 & -38.42 & This work \\
\hline$n$-Nonane & 0.000 & 0.000 & 0.000 & 0.000 & 4.182 & 1.3767 & -43.21 & This work \\
\hline$n$-Decane & 0.000 & 0.000 & 0.000 & 0.000 & 4.686 & 1.5176 & -47.79 & This work \\
\hline$n$-Dodecane & 0.000 & 0.000 & 0.000 & 0.000 & 5.696 & 1.7994 & -57.13 & This work \\
\hline$n$-Hexadecane & 0.000 & 0.000 & 0.000 & 0.000 & 7.714 & 2.3630 & -75.54 & 34 \\
\hline Tetradecane & 0.000 & 0.000 & 0.000 & 0.000 & 6.705 & 2.0812 & -65.95 & 35 \\
\hline Cyclohexane & 0.310 & 0.100 & 0.000 & 0.000 & 2.964 & 0.8454 & -30.58 & 49 \\
\hline Dichloromethane & 0.390 & 0.570 & 0.100 & 0.050 & 2.019 & 0.4943 & -28.48 & This work \\
\hline Trichloromethane & 0.430 & 0.490 & 0.150 & 0.020 & 2.480 & 0.6167 & -31.70 & This work \\
\hline Tetrachloromethane & 0.460 & 0.380 & 0.000 & 0.000 & 2.823 & 0.7391 & -32.65 & This work \\
\hline Tetrachloroethene & 0.639 & 0.440 & 0.000 & 0.000 & 3.584 & 0.8370 & -39.06 & 36 \\
\hline Trichloroethene & 0.520 & 0.370 & 0.080 & 0.030 & 2.997 & 0.7146 & -34.79 & 36 \\
\hline
\end{tabular}




\begin{tabular}{|c|c|c|c|c|c|c|c|c|}
\hline Diethyl ether & 0.041 & 0.250 & 0.000 & 0.450 & 2.015 & 0.7309 & -28.88 & 50 \\
\hline Dipropyl ether & 0.008 & 0.250 & 0.000 & 0.450 & 2.954 & 1.0127 & -37.15 & 50 \\
\hline Methyl tert-butyl ether & 0.024 & 0.210 & 0.000 & 0.590 & 2.372 & 0.8720 & -32.10 & 37 \\
\hline Dimethoxymethane & 0.099 & 0.460 & 0.000 & 0.520 & 1.894 & 0.6487 & -29.66 & 51 \\
\hline 1,2-Dimethoxyethane & 0.116 & 0.670 & 0.000 & 0.680 & 2.654 & 0.7896 & -38.95 & 51 \\
\hline Tetrahydrofuran & 0.289 & 0.520 & 0.000 & 0.480 & 2.636 & 0.6223 & -34.71 & 51 \\
\hline Tetrahydropyran & 0.296 & 0.490 & 0.000 & 0.480 & 3.013 & 0.7632 & -39.89 & 51 \\
\hline 1,4-Dioxane & 0.329 & 0.750 & 0.000 & 0.640 & 2.892 & 0.6810 & -39.13 & 51 \\
\hline 2-Methyltetrahydrofuran & 0.241 & 0.480 & 0.000 & 0.530 & 2.820 & 0.7632 & -33.56 & 52 \\
\hline Acetone & 0.179 & 0.700 & 0.040 & 0.490 & 1.696 & 0.5470 & -31.31 & This work \\
\hline Butanone & 0.166 & 0.700 & 0.000 & 0.510 & 2.287 & 0.6879 & -35.80 & 53 \\
\hline Pentan-2-one & 0.143 & 0.680 & 0.000 & 0.510 & 2.755 & 0.8288 & -39.64 & This work \\
\hline Heptan-2-one & 0.123 & 0.680 & 0.000 & 0.510 & 3.760 & 1.1106 & -49.04 & This work \\
\hline Octan-2-one & 0.108 & 0.680 & 0.000 & 0.510 & 4.257 & 1.2515 & -53.43 & This work \\
\hline Nonan-2-one & 0.113 & 0.680 & 0.000 & 0.510 & 4.735 & 1.3924 & -57.83 & This work \\
\hline Acetophenone & 0.818 & 1.010 & 0.000 & 0.480 & 4.501 & 1.0140 & -55.12 & 38 \\
\hline Methyl acetate & 0.142 & 0.640 & 0.000 & 0.450 & 1.911 & 0.6057 & -32.14 & This work \\
\hline Ethyl acetate & 0.106 & 0.620 & 0.000 & 0.450 & 2.314 & 0.7466 & -35.78 & This work \\
\hline Propyl acetate & 0.092 & 0.600 & 0.000 & 0.450 & 2.819 & 0.8875 & -38.95 & This work \\
\hline Butyl acetate & 0.071 & 0.600 & 0.000 & 0.450 & 3.353 & 1.0284 & -44.31 & This work \\
\hline Methyl propionate & 0.128 & 0.600 & 0.000 & 0.450 & 2.431 & 0.7466 & -35.94 & This work \\
\hline Propyl propionate & 0.070 & 0.560 & 0.000 & 0.450 & 3.338 & 1.0284 & -45.38 & 58 \\
\hline Methyl salicylate & 0.850 & 0.840 & 0.020 & 0.470 & 5.025 & 1.1313 & -56.27 & This work \\
\hline Ethyl salicylate & 0.802 & 0.910 & 0.030 & 0.430 & 5.509 & 1.2722 & -62.31 & This work \\
\hline Methyl benzoate & 0.733 & 0.850 & 0.000 & 0.460 & 4.704 & 1.0726 & -56.31 & This work \\
\hline Ethyl benzoate & 0.689 & 0.850 & 0.000 & 0.460 & 5.075 & 1.2135 & -59.24 & This work \\
\hline Propyl benzoate & 0.675 & 0.800 & 0.000 & 0.460 & 5.718 & 1.3544 & -65.46 & This work \\
\hline Butyl benzoate & 0.668 & 0.800 & 0.000 & 0.460 & 6.210 & 1.4953 & -69.04 & This work \\
\hline Acetonitrile & 0.237 & 0.900 & 0.070 & 0.320 & 1.739 & 0.4042 & -30.68 & 56 \\
\hline Propionitrile & 0.162 & 0.900 & 0.020 & 0.360 & 2.082 & 0.5451 & -35.97 & This work \\
\hline Butyronitrile & 0.188 & 0.900 & 0.000 & 0.360 & 2.548 & 0.6860 & -39.12 & This work \\
\hline Benzonitrile & 0.742 & 1.110 & 0.000 & 0.330 & 4.039 & 0.8710 & -49.58 & This work \\
\hline
\end{tabular}




\begin{tabular}{|c|c|c|c|c|c|c|c|c|}
\hline Triethylamine & 0.101 & 0.150 & 0.000 & 0.790 & 3.040 & 1.0538 & -35.65 & 39 \\
\hline Tri- $n$-butylamine & 0.051 & 0.150 & 0.000 & 0.790 & 6.050 & 1.8998 & -61.70 & 39 \\
\hline$N, N$-Dimethylformamide & 0.367 & 1.310 & 0.000 & 0.740 & 3.173 & 0.6468 & -47.32 & 40 \\
\hline$N, N$-Dimethylacetamide & 0.363 & 1.380 & 0.000 & 0.800 & 3.639 & 0.7877 & -53.25 & This work \\
\hline Methanol & 0.278 & 0.440 & 0.430 & 0.470 & 0.970 & 0.3082 & -26.13 & 56 \\
\hline Ethanol & 0.246 & 0.420 & 0.370 & 0.480 & 1.485 & 0.4491 & -30.40 & 56 \\
\hline Propan-1-ol & 0.236 & 0.420 & 0.370 & 0.480 & 2.031 & 0.5900 & -33.90 & 57 \\
\hline Butan-1-ol & 0.224 & 0.420 & 0.370 & 0.480 & 2.601 & 0.7309 & -35.83 & This work \\
\hline Pentan-1-ol & 0.219 & 0.420 & 0.370 & 0.480 & 3.106 & 0.8718 & -42.18 & This work \\
\hline Hexan-1-ol & 0.210 & 0.420 & 0.370 & 0.480 & 3.610 & 1.0127 & -46.31 & This work \\
\hline Octan-1-ol & 0.199 & 0.420 & 0.370 & 0.480 & 4.619 & 1.2945 & -56.49 & This work \\
\hline Decan-1-ol & 0.191 & 0.420 & 0.370 & 0.480 & 5.628 & 1.5763 & -66.43 & This work \\
\hline 2-Propanol & 0.212 & 0.360 & 0.330 & 0.560 & 1.764 & 0.5900 & -31.83 & 57 \\
\hline 2-Chlorophenol & 0.853 & 0.880 & 0.320 & 0.310 & 4.178 & 0.8976 & -57.14 & This work \\
\hline 2-Methoxyphenol & 0.837 & 0.910 & 0.220 & 0.520 & 4.449 & 0.9747 & -56.72 & This work \\
\hline 3-Methoxyphenol & 0.879 & 1.170 & 0.590 & 0.380 & 4.803 & 0.9747 & -67.85 & This work \\
\hline 4-Methoxyphenol & 0.900 & 1.170 & 0.570 & 0.480 & 4.773 & 0.9747 & -63.37 & This work \\
\hline Benzene & 0.610 & 0.520 & 0.000 & 0.140 & 2.786 & 0.7164 & -33.82 & 41 \\
\hline Toluene & 0.601 & 0.520 & 0.000 & 0.140 & 3.325 & 0.8573 & -38.45 & 41 \\
\hline Ethylbenzene & 0.613 & 0.510 & 0.000 & 0.150 & 3.788 & 0.9982 & -43.00 & 55 \\
\hline$o$-Xylene & 0.663 & 0.560 & 0.000 & 0.160 & 3.939 & 0.9982 & -43.83 & 55 \\
\hline$m$-Xylene & 0.623 & 0.520 & 0.000 & 0.160 & 3.839 & 0.9982 & -43.12 & 55 \\
\hline$p$-Xylene & 0.613 & 0.520 & 0.000 & 0.160 & 3.839 & 0.9982 & -42.85 & 55 \\
\hline Anisole & 0.710 & 0.750 & 0.000 & 0.290 & 3.890 & 0.9160 & -46.63 & 42 \\
\hline Mesitylene & 0.649 & 0.520 & 0.000 & 0.190 & 4.344 & 1.1391 & -47.59 & This work \\
\hline Biphenyl & 1.360 & 0.990 & 0.000 & 0.260 & 6.014 & 1.3242 & -64.90 & 34 \\
\hline Anthracene & 2.290 & 1.340 & 0.000 & 0.280 & 7.568 & 1.4540 & -77.80 & 34 \\
\hline Naphthalene & 1.340 & 0.920 & 0.000 & 0.200 & 5.161 & 1.0854 & -55.10 & 34 \\
\hline 1-Chloronaphthalene & 1.417 & 1.000 & 0.000 & 0.140 & 5.856 & 1.2078 & -63.47 & 34 \\
\hline Chlorobenzene & 0.718 & 0.650 & 0.000 & 0.070 & 3.657 & 0.8388 & -41.00 & 34 \\
\hline Fluorobenzene & 0.477 & 0.570 & 0.000 & 0.100 & 2.788 & 0.7341 & -34.65 & 34 \\
\hline Bromobenzene & 0.882 & 0.730 & 0.000 & 0.090 & 4.041 & 0.8914 & -44.04 & 34 \\
\hline
\end{tabular}




\begin{tabular}{|c|c|c|c|c|c|c|c|c|}
\hline Iodobenzene & 1.188 & 0.820 & 0.000 & 0.120 & 4.502 & 0.9746 & -49.37 & 34 \\
\hline 1,2-Dichlorobenzene & 0.872 & 0.780 & 0.000 & 0.040 & 4.518 & 0.9612 & -49.34 & 34 \\
\hline 1,3-Dichlorobenzene & 0.847 & 0.730 & 0.000 & 0.020 & 4.410 & 0.9612 & -46.69 & 34 \\
\hline 1,4-Dichlorobenzene & 0.825 & 0.750 & 0.000 & 0.020 & 4.435 & 0.9612 & -47.10 & 34 \\
\hline 1,2,4,5-Tetrachlorobenzene & 1.160 & 0.860 & 0.000 & 0.000 & 5.926 & 1.4164 & -59.70 & 34 \\
\hline Hexachlorobenzene & 1.490 & 0.990 & 0.000 & 0.000 & 7.624 & 1.4508 & -76.96 & 34 \\
\hline 1,3,5-Trichlorobenzene & 0.980 & 0.730 & 0.000 & 0.000 & 5.045 & 1.0836 & -51.04 & 34 \\
\hline 1,3,5-Tribromobenzene & 1.450 & 1.020 & 0.000 & 0.000 & 6.307 & 1.2410 & -63.84 & 34 \\
\hline Pyrrole & 0.613 & 0.730 & 0.410 & 0.290 & 2.865 & 0.5570 & -40.20 & 42 \\
\hline$N$-Methylpyrrole & 0.559 & 0.790 & 0.000 & 0.310 & 2.923 & 0.7180 & -40.80 & 42 \\
\hline Aniline & 0.955 & 0.960 & 0.260 & 0.410 & 3.934 & 0.8160 & -52.82 & 43 \\
\hline Pyridine & 0.631 & 0.840 & 0.000 & 0.520 & 3.022 & 0.6753 & -40.18 & 48 \\
\hline 2-Picoline & 0.598 & 0.750 & 0.000 & 0.580 & 3.422 & 0.8162 & -43.43 & 48 \\
\hline 3-Picoline & 0.631 & 0.810 & 0.000 & 0.540 & 3.631 & 0.8162 & -44.99 & This work \\
\hline 4-Picoline & 0.630 & 0.820 & 0.000 & 0.540 & 3.640 & 0.8162 & -44.74 & This work \\
\hline 2,4-Dimethylpyridine & 0.634 & 0.760 & 0.000 & 0.630 & 4.006 & 0.9571 & -48.53 & 44 \\
\hline 2,6-Dimethylpyridine & 0.607 & 0.700 & 0.000 & 0.630 & 3.760 & 0.9571 & -46.61 & 44 \\
\hline 2-Chloropyridine & 0.738 & 1.040 & 0.000 & 0.370 & 3.875 & 0.7977 & -50.28 & 48 \\
\hline 3-Chloropyridine & 0.732 & 0.830 & 0.000 & 0.400 & 3.783 & 0.7977 & -46.94 & 48 \\
\hline 3-Cyanopyridine & 0.750 & 1.260 & 0.000 & 0.620 & 4.164 & 0.8300 & -53.90 & 48 \\
\hline 4-Cyanopyridine & 0.750 & 1.210 & 0.000 & 0.590 & 4.033 & 0.8300 & -52.50 & 48 \\
\hline$N$-Methylimidazole & 0.589 & 0.950 & 0.000 & 0.800 & 3.805 & 0.6772 & -52.89 & 45 \\
\hline Indole & 1.200 & 1.260 & 0.440 & 0.180 & 5.310 & 0.9464 & -63.98 & This work \\
\hline Tetramethyltin & 0.324 & 0.110 & 0.000 & 0.100 & 2.651 & 1.0431 & -30.71 & 49 \\
\hline Iodine & 1.398 & 0.670 & 0.280 & 0.000 & 3.681 & 0.6250 & -40.20 & 46 \\
\hline Pyrazole & 0.620 & 1.000 & 0.540 & 0.450 & 3.151 & 0.5363 & -47.40 & This work \\
\hline$N$-Methylpyrazole & 0.521 & 0.970 & 0.000 & 0.550 & 3.215 & 0.6722 & -44.52 & 45 \\
\hline Dimethyl sulfoxide & 0.522 & 1.740 & 0.000 & 0.880 & 3.459 & 0.6126 & -51.10 & 54 \\
\hline 2,6-Dimethoxyphenol & 0.840 & 1.410 & 0.130 & 0.710 & 5.677 & 1.1743 & -78.22 & This work \\
\hline$N$-Methyl-2-pyrrolidone & 0.491 & 1.300 & 0.000 & 0.790 & 3.832 & 0.8200 & -57.01 & 47 \\
\hline Isoquinoline & 1.211 & 1.000 & 0.000 & 0.540 & 5.595 & 1.0443 & -60.28 & 44 \\
\hline cis-1,2-Dichloroethene & 0.440 & 0.610 & 0.110 & 0.050 & 2.439 & 0.5922 & -30.27 & 36 \\
\hline
\end{tabular}




\begin{tabular}{lrlllllll}
\hline trans-1,2-Dichloroethene & 0.430 & 0.410 & 0.090 & 0.050 & 2.278 & 0.5922 & -30.30 & 36 \\
Ammonia & 0.140 & 0.390 & 0.160 & 0.560 & 0.319 & 0.2084 & -14.90 & 59 \\
Hydrogen sulfide & 0.350 & 0.310 & 0.100 & 0.070 & 0.723 & 0.2721 & -12.10 & 59 \\
1,2-Propylene oxide & 0.243 & 0.740 & 0.070 & 0.350 & 1.775 & 0.4814 & -28.69 & 50 \\
\hline
\end{tabular}

26

27 
29 Table 5. Values of the gas to 1,2-dichlorobenzene solvation enthalpies in $\mathrm{kJ} \cdot \mathrm{mol}^{-1}$ at $298 \mathrm{~K}, \Delta_{\text {solv }} H^{A / C_{6} H_{4} \mathrm{Cl}_{2}}$, for 94 solutes 30 together with the solute descriptors

\begin{tabular}{|c|c|c|c|c|c|c|c|c|}
\hline Solute (A) & $\mathbf{E}$ & $\mathbf{S}$ & $\mathbf{A}$ & B & $\mathbf{L}$ & $\mathbf{V}$ & $\Delta_{\text {solv }} H^{A / C_{6} H_{4} C l 2}$ & Ref \\
\hline$n$-Hexane & 0.000 & 0.000 & 0.000 & 0.000 & 2.668 & 0.9540 & -28.86 & This work \\
\hline$n$-Heptane & 0.000 & 0.000 & 0.000 & 0.000 & 3.173 & 1.0949 & -33.77 & This work \\
\hline$n$-Octane & 0.000 & 0.000 & 0.000 & 0.000 & 3.677 & 1.2358 & -38.50 & This work \\
\hline$n$-Nonane & 0.000 & 0.000 & 0.000 & 0.000 & 4.182 & 1.3767 & -43.33 & This work \\
\hline$n$-Decane & 0.000 & 0.000 & 0.000 & 0.000 & 4.686 & 1.5176 & -47.90 & This work \\
\hline$n$-Dodecane & 0.000 & 0.000 & 0.000 & 0.000 & 5.696 & 1.7994 & -57.42 & This work \\
\hline$n$-Tetradecane & 0.000 & 0.000 & 0.000 & 0.000 & 6.705 & 2.0812 & -67.42 & 60 \\
\hline Cyclohexane & 0.310 & 0.100 & 0.000 & 0.000 & 2.964 & 0.8454 & -30.07 & 34 \\
\hline Dichloromethane & 0.390 & 0.570 & 0.100 & 0.050 & 2.019 & 0.4943 & -27.84 & This work \\
\hline 1-Chlorobutane & 0.210 & 0.400 & 0.000 & 0.100 & 2.722 & 0.7946 & -33.40 & This work \\
\hline 1-Chlorohexane & 0.201 & 0.400 & 0.000 & 0.100 & 3.777 & 1.0770 & -42.55 & 61 \\
\hline 1,2-Dichloropropane & 0.369 & 0.630 & 0.000 & 0.170 & 2.836 & 0.7761 & -35.04 & This work \\
\hline Trichloroethene & 0.520 & 0.370 & 0.080 & 0.030 & 2.997 & 0.7146 & -35.71 & 36 \\
\hline Trichloromethane & 0.430 & 0.490 & 0.150 & 0.020 & 2.480 & 0.6167 & -31.05 & This work \\
\hline Tetrachloroethene & 0.639 & 0.440 & 0.000 & 0.000 & 3.584 & 0.8370 & -38.47 & 36 \\
\hline Diethyl ether & 0.041 & 0.250 & 0.000 & 0.450 & 2.015 & 0.7309 & -26.19 & This work \\
\hline Di- $n$-butyl ether & 0.000 & 0.250 & 0.000 & 0.450 & 3.924 & 1.2950 & -44.80 & This work \\
\hline Tetrahydrofuran & 0.289 & 0.520 & 0.000 & 0.480 & 2.636 & 0.6223 & -33.81 & This work \\
\hline 1,4-Dioxane & 0.329 & 0.750 & 0.000 & 0.640 & 2.892 & 0.6810 & -39.41 & This work \\
\hline Acetone & 0.179 & 0.700 & 0.040 & 0.490 & 1.696 & 0.5470 & -30.74 & This work \\
\hline Butanone & 0.166 & 0.700 & 0.000 & 0.510 & 2.287 & 0.6879 & -35.26 & This work \\
\hline Pentan-2-one & 0.143 & 0.680 & 0.000 & 0.510 & 2.755 & 0.8288 & -39.32 & This work \\
\hline Heptan-2-one & 0.123 & 0.680 & 0.000 & 0.510 & 3.760 & 1.1106 & -48.71 & This work \\
\hline Octan-2-one & 0.108 & 0.680 & 0.000 & 0.510 & 4.257 & 1.2515 & -53.30 & This work \\
\hline Nonan-2-one & 0.113 & 0.680 & 0.000 & 0.510 & 4.735 & 1.3924 & -57.72 & This work \\
\hline Acetophenone & 0.818 & 1.010 & 0.000 & 0.480 & 4.501 & 1.014 & -54.62 & This work \\
\hline Benzophenone & 1.447 & 1.500 & 0.000 & 0.500 & 6.852 & 1.4810 & -78.38 & This work \\
\hline Methyl acetate & 0.142 & 0.640 & 0.000 & 0.450 & 1.911 & 0.6057 & -31.84 & This work \\
\hline
\end{tabular}




\begin{tabular}{|c|c|c|c|c|c|c|c|c|}
\hline Ethyl acetate & 0.106 & 0.620 & 0.000 & 0.450 & 2.314 & 0.7466 & -35.30 & This work \\
\hline Propyl acetate & 0.092 & 0.600 & 0.000 & 0.450 & 2.819 & 0.8875 & -38.46 & This work \\
\hline Butyl acetate & 0.071 & 0.600 & 0.000 & 0.450 & 3.353 & 1.0284 & -43.70 & This work \\
\hline Methyl propionate & 0.128 & 0.600 & 0.000 & 0.450 & 2.431 & 0.7466 & -35.99 & This work \\
\hline Methylsalicylate & 0.850 & 0.840 & 0.020 & 0.470 & 5.025 & 1.1313 & -56.65 & This work \\
\hline Ethylsalicylate & 0.802 & 0.910 & 0.030 & 0.430 & 5.509 & 1.2722 & -62.30 & This work \\
\hline Methyl benzoate & 0.733 & 0.850 & 0.000 & 0.460 & 4.704 & 1.0726 & -56.25 & This work \\
\hline Ethyl benzoate & 0.689 & 0.850 & 0.000 & 0.460 & 5.075 & 1.2135 & -59.08 & This work \\
\hline Propyl benzoate & 0.675 & 0.800 & 0.000 & 0.460 & 5.718 & 1.3544 & -65.32 & This work \\
\hline Butyl benzoate & 0.668 & 0.800 & 0.000 & 0.460 & 6.210 & 1.4953 & -69.11 & This work \\
\hline Acetonitrile & 0.237 & 0.900 & 0.070 & 0.320 & 1.739 & 0.4042 & -29.76 & This work \\
\hline Propionitrile & 0.162 & 0.900 & 0.020 & 0.360 & 2.082 & 0.5451 & -35.14 & This work \\
\hline Butyronitrile & 0.188 & 0.900 & 0.000 & 0.360 & 2.548 & 0.6860 & -38.38 & This work \\
\hline Benzonitrile & 0.742 & 1.110 & 0.000 & 0.330 & 4.039 & 0.8710 & -49.48 & This work \\
\hline Triethylamine & 0.101 & 0.150 & 0.000 & 0.790 & 3.040 & 1.0538 & -36.195 & 62 \\
\hline Tri- $n$-butylamine & 0.051 & 0.150 & 0.000 & 0.790 & 6.050 & 1.8998 & -60.53 & This work \\
\hline$N$-Methylpyrrole & 0.559 & 0.790 & 0.000 & 0.310 & 2.923 & 0.7180 & -40.50 & 41 \\
\hline$N, N$-Dimethylformamide & 0.367 & 1.310 & 0.000 & 0.740 & 3.173 & 0.6468 & -47.07 & This work \\
\hline$N, N$-Dimethylacetamide & 0.363 & 1.380 & 0.000 & 0.800 & 3.639 & 0.7877 & -52.91 & This work \\
\hline Methanol & 0.278 & 0.440 & 0.430 & 0.470 & 0.970 & 0.3082 & -23.00 & This work \\
\hline Ethanol & 0.246 & 0.420 & 0.370 & 0.480 & 1.485 & 0.4491 & -26.44 & This work \\
\hline Propan-1-ol & 0.236 & 0.420 & 0.370 & 0.480 & 2.031 & 0.5900 & -31.54 & This work \\
\hline Butan-1-ol & 0.224 & 0.420 & 0.370 & 0.480 & 2.601 & 0.7309 & -35.84 & This work \\
\hline Pentan-1-ol & 0.219 & 0.420 & 0.370 & 0.480 & 3.106 & 0.8718 & -42.10 & This work \\
\hline Hexan-1-ol & 0.210 & 0.420 & 0.370 & 0.480 & 3.610 & 1.0127 & -46.10 & This work \\
\hline Octan-1-ol & 0.199 & 0.420 & 0.370 & 0.480 & 4.619 & 1.2945 & -56.13 & This work \\
\hline Decan-1-ol & 0.191 & 0.420 & 0.370 & 0.480 & 5.628 & 1.5763 & -66.10 & This work \\
\hline 2-Chlorophenol & 0.853 & 0.880 & 0.320 & 0.310 & 4.178 & 0.8976 & -55.11 & This work \\
\hline 2-Methoxyphenol & 0.837 & 0.910 & 0.220 & 0.520 & 4.449 & 0.9750 & -56.86 & This work \\
\hline 3-Methoxyphenol & 0.879 & 1.170 & 0.590 & 0.380 & 4.803 & 0.9747 & -65.67 & This work \\
\hline 4-Methoxyphenol & 0.900 & 1.170 & 0.570 & 0.480 & 4.773 & 0.9747 & -62.37 & This work \\
\hline 4-Fluorophenol & 0.670 & 0.970 & 0.630 & 0.230 & 3.844 & 0.7928 & -48.96 & 63 \\
\hline
\end{tabular}




\begin{tabular}{|c|c|c|c|c|c|c|c|c|}
\hline Benzene & 0.610 & 0.520 & 0.000 & 0.140 & 2.786 & 0.7164 & -33.20 & 41 \\
\hline Toluene & 0.601 & 0.520 & 0.000 & 0.140 & 3.325 & 0.8573 & -38.18 & 41 \\
\hline$o$-Xylene & 0.663 & 0.560 & 0.000 & 0.160 & 3.939 & 0.9982 & -43.74 & This work \\
\hline$m$-Xylene & 0.623 & 0.520 & 0.000 & 0.160 & 3.839 & 0.9982 & -42.87 & This work \\
\hline$p$-Xylene & 0.613 & 0.520 & 0.000 & 0.160 & 3.839 & 0.9982 & -42.69 & This work \\
\hline Anisole & 0.710 & 0.750 & 0.000 & 0.290 & 3.890 & 0.9160 & -46.18 & This work \\
\hline Mesitylene & 0.649 & 0.520 & 0.000 & 0.190 & 4.344 & 1.1391 & -47.72 & This work \\
\hline Biphenyl & 1.360 & 0.990 & 0.000 & 0.260 & 6.014 & 1.3242 & -65.64 & This work \\
\hline Naphthalene & 1.340 & 0.920 & 0.000 & 0.200 & 5.161 & 1.0854 & -55.25 & This work \\
\hline Anthracene & 2.290 & 1.340 & 0.000 & 0.280 & 7.568 & 1.4540 & -79.54 & This work \\
\hline Chlorobenzene & 0.718 & 0.650 & 0.000 & 0.070 & 3.657 & 0.8388 & -40.76 & This work \\
\hline Fluorobenzene & 0.477 & 0.570 & 0.000 & 0.100 & 2.788 & 0.7341 & -34.21 & This work \\
\hline Bromobenzene & 0.882 & 0.730 & 0.000 & 0.090 & 4.041 & 0.8914 & -44.17 & This work \\
\hline 1,2-Dichlorobenzene & 0.872 & 0.780 & 0.000 & 0.040 & 4.518 & 0.9612 & -49.60 & 34 \\
\hline Pyrrole & 0.613 & 0.730 & 0.410 & 0.290 & 2.865 & 0.5570 & -40.14 & 41 \\
\hline Pyridine & 0.631 & 0.840 & 0.000 & 0.520 & 3.022 & 0.6753 & -38.88 & This work \\
\hline 2-Picoline & 0.598 & 0.750 & 0.000 & 0.580 & 3.422 & 0.8162 & -41.89 & This work \\
\hline 3-Picoline & 0.631 & 0.810 & 0.000 & 0.540 & 3.631 & 0.8162 & -43.55 & This work \\
\hline 4-Picoline & 0.630 & 0.820 & 0.000 & 0.540 & 3.64 & 0.8162 & -43.27 & This work \\
\hline$N$-Methylimidazole & 0.589 & 0.950 & 0.000 & 0.800 & 3.805 & 0.6772 & -52.27 & 45 \\
\hline Indole & 1.200 & 1.260 & 0.440 & 0.180 & 5.310 & 0.9464 & -65.07 & This work \\
\hline Pyrazole & 0.620 & 1.000 & 0.540 & 0.450 & 3.151 & 0.5363 & -49.61 & This work \\
\hline Dimethyl sulfoxide & 0.522 & 1.740 & 0.000 & 0.880 & 3.459 & 0.6126 & -49.66 & 62 \\
\hline$N$-Methylpyrazole & 0.521 & 0.970 & 0.000 & 0.550 & 3.215 & 0.6722 & -43.94 & 45 \\
\hline$N$-Methyl-2-pyrrolidone & 0.491 & 1.300 & 0.000 & 0.790 & 3.832 & 0.8200 & -56.78 & 47 \\
\hline cis-1,2-Dichloroehtene & 0.440 & 0.610 & 0.110 & 0.050 & 2.439 & 0.5922 & -29.77 & 36 \\
\hline trans-1,2- Dichloroehtene & 0.430 & 0.410 & 0.090 & 0.050 & 2.278 & 0.5922 & -30.01 & 36 \\
\hline 4-Fluoroanisole & 0.571 & 0.740 & 0.000 & 0.280 & 3.904 & 0.9337 & -48.08 & 63 \\
\hline 3-Fluorophenol & 0.667 & 0.976 & 0.680 & 0.170 & 3.844 & 0.7928 & -49.01 & 63 \\
\hline 2,6-Dimethoxyphenol & 0.840 & 1.410 & 0.130 & 0.710 & 5.677 & 1.1743 & -77.75 & This work \\
\hline 2-Hydoxyacetophenone & 0.948 & 1.320 & 0.000 & 0.370 & 5.341 & 1.0726 & -57.42 & This work \\
\hline 1,3-Dichlorobenzene & 0.847 & 0.730 & 0.000 & 0.020 & 4.410 & 0.9612 & -46.97 & 64 \\
\hline
\end{tabular}




\begin{tabular}{lcccccccc}
\hline Aniline & 0.955 & 0.960 & 0.260 & 0.410 & 3.934 & 0.8160 & -51.69 & This work \\
Dimethylamine & 0.189 & 0.300 & 0.080 & 0.660 & 1.600 & 0.4902 & -29.52 & 65 \\
\hline
\end{tabular}

31

32

33 
34 Table 6. Comparison Between Our Measured $\Delta_{\text {soln }} \mathrm{H}^{\mathrm{A} / \text { Solvent }}$ (in $\mathrm{kJ} \mathrm{mol}^{-1}$ ) Values for Solutes

35 Dissolved in Chlorobenzene and 1,2-Dichlorobenzene at $298 \mathrm{~K}$ and Published Literature Data

\begin{tabular}{|l|c|c|l|}
\hline Solute & $\Delta_{\text {soln }} \mathrm{H}^{\mathrm{A} / \text { Solvent }}$ (our) & $\Delta_{\text {soln }} \mathrm{H}^{\mathrm{A} / \text { Solvent }}$ (lit) & Ref. \\
\hline Solvent = Chlorobenzene & & & \\
\hline 1-Butanol & 15.87 & 13.10 & 77 \\
\hline 1-Pentanol & 15.22 & 14.87 & 78 \\
\hline 1-Hexanol & 15.22 & 14.44 & 78 \\
\hline Benzonitrile & 0.52 & 0.41 & 79 \\
\hline & & & \\
\hline Solvent =1,2-Dichlorobenzene & & & \\
\hline Hexane & 2.64 & 3.41 & 61 \\
\hline$\underline{\text { o-Xylene }}$ & -0.35 & -0.31 & 80 \\
\hline$m$-Xylene & -0.27 & -0.26 & 80 \\
\hline$p$-Xylene & -0.30 & -0.28 & 80 \\
\hline Chlorobenzene & 0.26 & 0.25 & 64 \\
\hline
\end{tabular}

36

37 
38 Table 7. Regression coefficients (solvent parameters) of Eqs. (1) and (2) for benzene and its 39 chlorine derivatives.

40

\begin{tabular}{lcccccc}
\hline Solvent & $\mathrm{c}$ & $\mathrm{e}$ & $\mathrm{s}$ & $\mathrm{a}$ & $\mathrm{b}$ & $\mathrm{l}(\mathrm{v})$ \\
\hline Benzene & -4.637 & 4.446 & -12.599 & -9.775 & -4.023 & -8.488 \\
Benzene (V) & 4.391 & -5.422 & -21.268 & -11.797 & -3.118 & $-31.674^{a}$ \\
Methylbenzene & -5.291 & 3.511 & -12.943 & -6.317 & -4.434 & -8.382 \\
Methylbenzene (V) & 4.199 & -7.143 & -20.440 & -10.006 & -3.439 & $-32.235^{\mathrm{a}}$ \\
1,4-Dimethylbenzene & -6.265 & 6.460 & -9.862 & -10.775 & 0 & -9.318 \\
1,4-Dimethylbenzene (V) & 1.703 & -3.466 & -18.074 & -14.109 & 0 & $-33.618^{\mathrm{a}}$ \\
1,3,5-Trimethylbenzene & -5.488 & 6.646 & -9.602 & -10.828 & 0 & -9.538 \\
1,3,5-Trimethylbenzene (V) & 2.940 & -3.805 & -18.981 & -14.011 & 0 & $-34.238^{\mathrm{a}}$ \\
Chlorobenzene & -5.377 & 5.383 & -10.333 & -11.478 & -5.038 & -9.041 \\
Chlorobenzene (V) & 5.534 & -4.164 & -20.543 & -16.252 & -4.832 & $-34.675^{a}$ \\
1,2-Dichlorobenzene & -4.609 & 3.975 & -8.947 & -8.518 & -5.928 & -9.182 \\
1,2-Dichlorobenzene (V) & 1.234 & -5.635 & -16.692 & -12.033 & -5.196 & $-32.033^{a}$ \\
\hline
\end{tabular}

"value of "v" coefficient in Eqn. (2)

42 
Table 8. Enthalpies of weak hydrogen bonding of benzene and chlorobenzenes with different proton donor solutes calculated by Abraham-Acree and Solomonov methods.

\begin{tabular}{|c|c|c|c|c|c|c|c|c|c|}
\hline \multirow[t]{3}{*}{ Solute (A) } & \multicolumn{3}{|c|}{$\Delta_{\mathrm{HB}} H^{\mathrm{A} \ldots \mathrm{S}}$} & \multicolumn{3}{|c|}{$\Delta_{\mathrm{HB}} H^{\mathrm{A} \ldots \mathrm{S}}$} & \multicolumn{3}{|c|}{$\Delta_{\mathrm{HB}} H^{\mathrm{A} \ldots \mathrm{S}}$} \\
\hline & \multicolumn{3}{|c|}{ Benzene } & \multicolumn{3}{|c|}{ Chlorobenzene } & \multicolumn{3}{|c|}{ 1,2-Dichlorobenzene } \\
\hline & $\mathrm{L}^{\mathrm{a}}$ & $\mathrm{V}^{\mathrm{b}}$ & $\mathrm{S}^{\mathrm{c}}$ & $\mathrm{L}^{\mathrm{a}}$ & $\mathrm{V}^{\mathrm{b}}$ & $\mathrm{S}^{\mathrm{c}}$ & $\mathrm{L}^{\mathrm{a}}$ & $\mathrm{V}^{\mathrm{b}}$ & $\mathrm{S}^{\mathrm{c}}$ \\
\hline Methanol & -4.2 & -5.1 & -3.0 & -4.9 & -7.0 & -4.9 & -3.7 & -5.2 & -1.8 \\
\hline Ethanol & -3.6 & -4.4 & -3.4 & -4.2 & -6.0 & -5.1 & -3.2 & -4.5 & -1.2 \\
\hline Propan-1-ol & -3.6 & -4.4 & - & -4.2 & -6.0 & -3.3 & -3.2 & -4.5 & -1.0 \\
\hline Butan-1-ol & -3.6 & -4.4 & -0.9 & -4.2 & -6.0 & -2.0 & -3.2 & -4.5 & -2.1 \\
\hline Pentan-1-ol & -3.6 & -4.4 & -0.4 & -4.2 & -6.0 & -2.8 & -3.2 & -4.5 & -2.7 \\
\hline Hexan-1-ol & -3.6 & -4.4 & -0.7 & -4.2 & -6.0 & -2.2 & -3.2 & -4.5 & -2.1 \\
\hline Octan-1-ol & -3.6 & -4.4 & 0.2 & -4.2 & -6.0 & -2.3 & -3.2 & -4.5 & -1.9 \\
\hline Decan-1-ol & -3.6 & -4.4 & - & -4.2 & -6.0 & -1.4 & -3.2 & -4.5 & -1.0 \\
\hline 2-Methoxyphenol & -2.2 & -2.6 & - & -2.5 & -3.6 & -2.6 & -1.9 & -2.7 & -2.7 \\
\hline 3-Methoxyphenol & -5.8 & -7.0 & - & -6.8 & -9.6 & -6.0 & -5.0 & -7.2 & -3.9 \\
\hline 4-Methoxyphenol & -5.6 & -6.7 & - & -6.5 & -9.3 & -7.3 & -4.9 & -6.9 & -6.3 \\
\hline 2-Chlorophenol & -3.1 & -3.8 & - & -3.8 & -5.2 & & -2.7 & -3.9 & \\
\hline Pyrrole & -4.0 & -4.8 & -3.2 & -4.7 & -6.7 & -2.6 & -3.5 & -5.0 & -2.6 \\
\hline Indole & -4.3 & -5.2 & - & -5.1 & -7.2 & -3.5 & -3.7 & -5.3 & -4.6 \\
\hline Pyrazole & -5.3 & -6.4 & -5.5 & -6.2 & -8.8 & -5.2 & -4.6 & -6.6 & -7.5 \\
\hline Dichloromethane & -1.0 & -1.2 & - & -1.1 & -1.6 & -0.8 & -0.9 & -1.2 & -0.2 \\
\hline Trichloromethane & -1.5 & -1.8 & -2.5 & -1.7 & -2.4 & -1.2 & -1.3 & -1.8 & -0.5 \\
\hline Acetonitrile & -0.7 & -0.8 & -0.6 & -0.8 & -1.1 & -1.4 & -0.6 & -0.8 & -1.5 \\
\hline
\end{tabular}


${ }^{a}$ Calculated from the Abraham-Acree multiparameter correlations with L descriptor

${ }^{\mathrm{b}}$ Calculated from the Abraham-Acree multiparameter correlations with $\mathrm{V}$ descriptor

${ }^{\mathrm{c}}$ Calculated using Solomonov method 
Figure 1

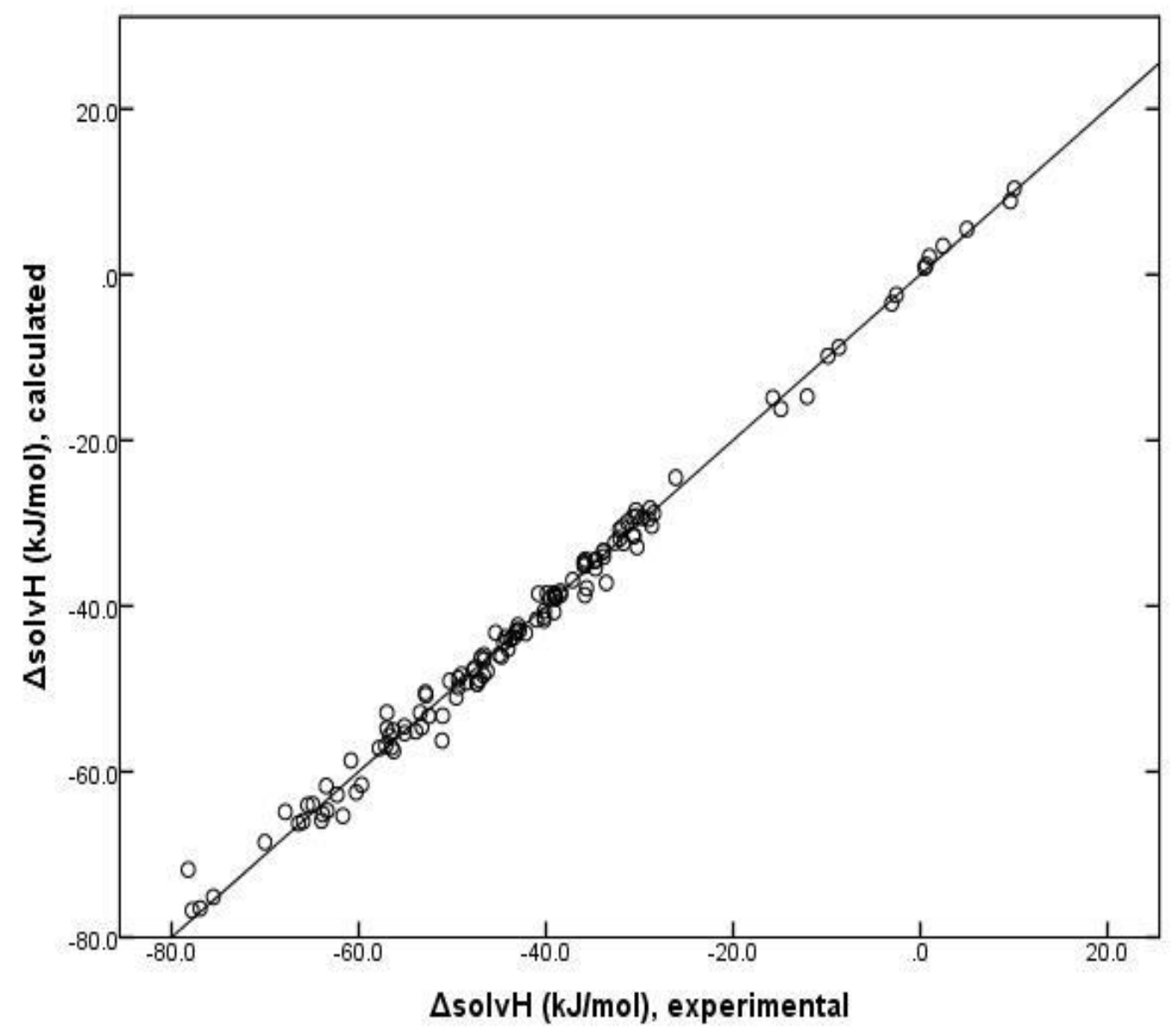

Figure 1. Comparison of experimental $\Delta_{s o l v} H^{A / C_{6} H_{5} C l}$ data and back-calculated values based on eqn. (3). 
Figure 2

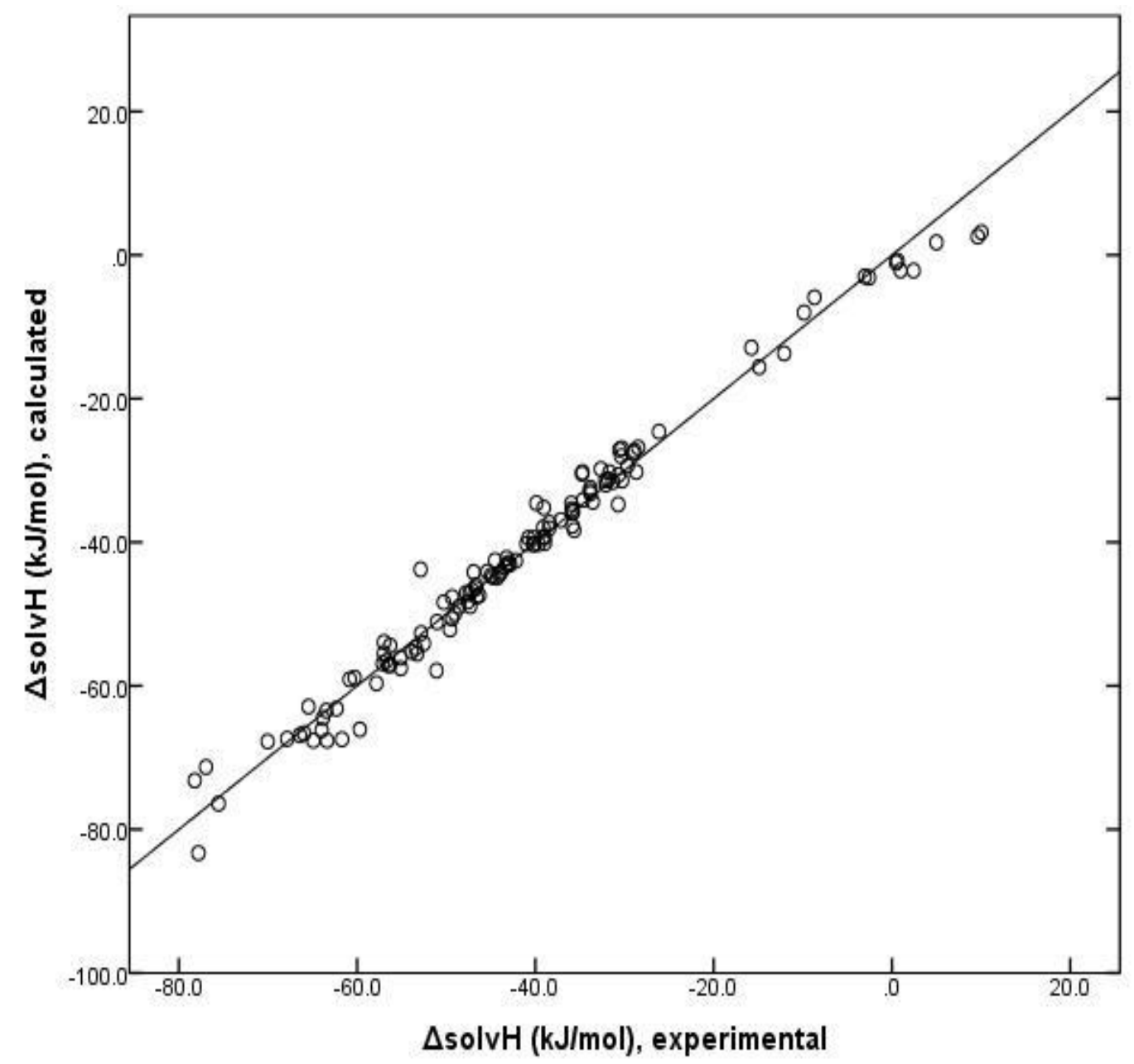

Figure 2. Comparison of experimental $\Delta_{s o l v} H^{A /{ }_{6} H_{5} C l}$ data and back-calculated values based on eqn. (4). 
Figure 3

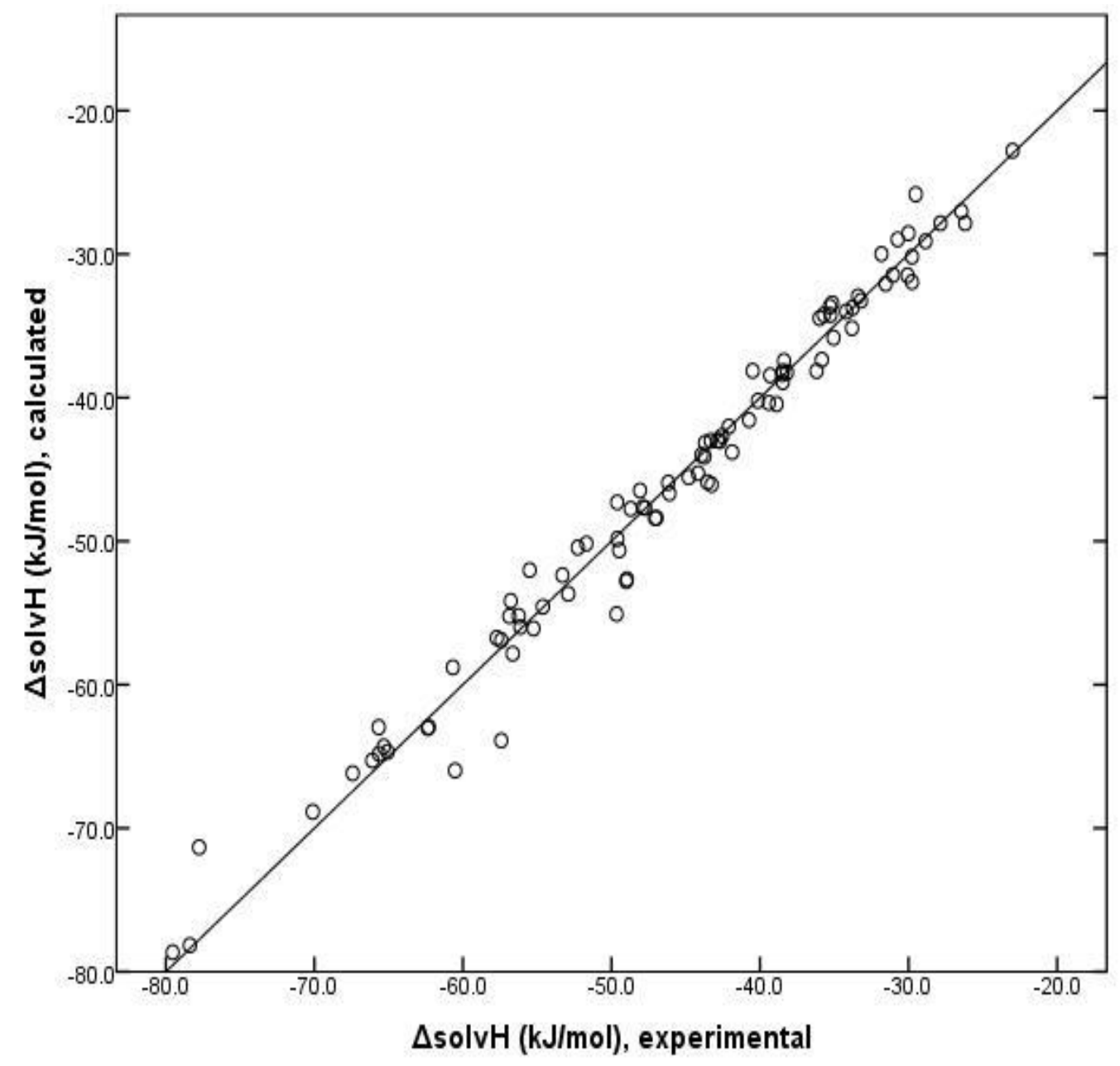

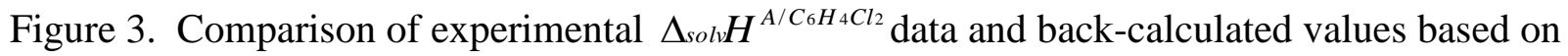
eqn. (7). 
Figure 4

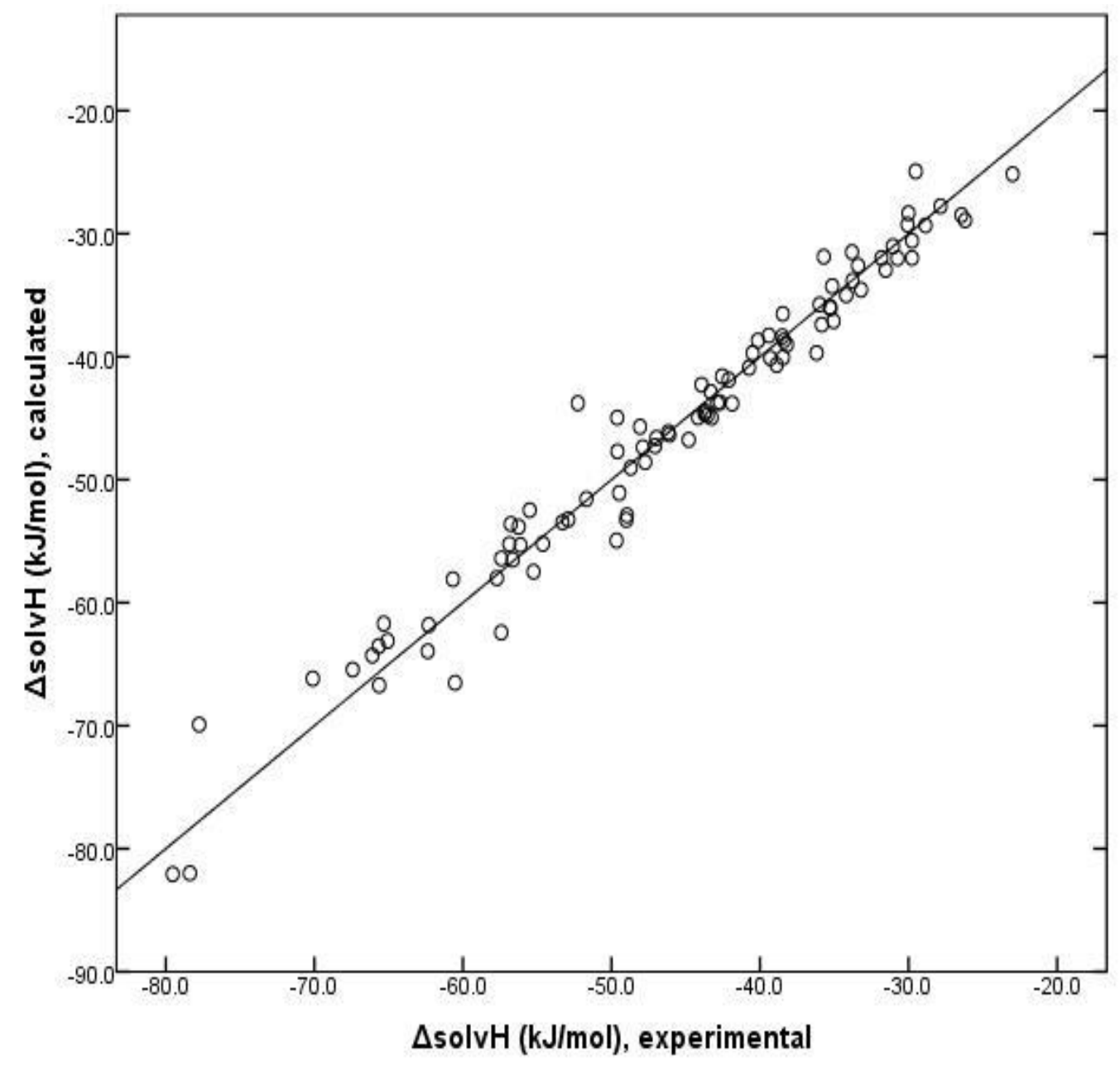

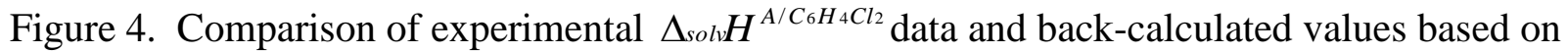
eqn. (8). 


\section{HIGHLIGHTS}

- Enthalpies of solution measured for 43 solutes dissolved in chlorobenzene

- Enthalpies of solution measured for 72 solutes dissolved in 1,2-dichlorobenzene

- Mathematical expressions derived for predicting enthalpies of solvation of solutes in chlorobenzene

- Mathematical expressions derived for predicting enthalpies of solvation of solutes in 1,2chlorobenzene 


\section{GRAPHICAL ABSTRACT}

\section{ABRAHAM MODEL CORRELATIONS FOR ENTHALPIES OF SOLVATION}

$$
\begin{gathered}
\Delta_{\text {solv }} H^{\mathrm{A} / \text { Solvent }}=c_{\mathrm{h}, \mathrm{l}}+\mathrm{e}_{\mathrm{h}, \mathrm{l}} \cdot \mathbf{E}+\mathrm{s}_{\mathrm{h}, \mathrm{l}} \cdot \mathbf{S}+\mathrm{a}_{\mathrm{h}, \mathrm{l}} \cdot \mathbf{A}+\mathrm{b}_{\mathrm{h}, \mathrm{l}} \cdot \mathbf{B}+\mathrm{l}_{\mathrm{h}, \mathrm{l}} \cdot \mathbf{L} \\
\Delta_{\text {solv }} H^{\mathrm{A} / \text { Solvent }}=\mathrm{c}_{\mathrm{h}, \mathrm{v}}+\mathrm{e}_{\mathrm{h}, \mathrm{v}} \cdot \mathbf{E}+\mathrm{s}_{\mathrm{h}, \mathrm{v}} \cdot \mathbf{S}+\mathrm{a}_{\mathrm{h}, \mathrm{v}} \cdot \mathbf{A}+\mathrm{b}_{\mathrm{h}, \mathrm{v}} \cdot \mathbf{B}+\mathrm{v}_{\mathrm{h}, \mathrm{v}} \cdot \mathbf{V}
\end{gathered}
$$

SOLUTE IN GAS PHASE

$\Delta_{\text {solv }} H^{\mathrm{A} / \mathrm{C} 6 \mathrm{H} 5 \mathrm{Cl}}$

$$
\downarrow
$$

$\mathrm{C}_{6} \mathrm{H}_{5} \mathrm{Cl} \quad \mathrm{C}_{6} \mathrm{H}_{5} \mathrm{Cl} \quad \mathrm{C}_{6} \mathrm{H}_{5} \mathrm{Cl}$

$\mathrm{C}_{6} \mathrm{H}_{5} \mathrm{Cl} \quad \mathrm{C}_{6} \mathrm{H}_{5} \mathrm{Cl} \quad \mathrm{C}_{6} \mathrm{H}_{5} \mathrm{Cl}$

$\mathrm{C}_{6} \mathrm{H}_{5} \mathrm{Cl} \quad \mathrm{C}_{6} \mathrm{H}_{5} \mathrm{Cl} \quad \mathrm{C}_{6} \mathrm{H}_{5} \mathrm{Cl}$

$\mathrm{C}_{6} \mathrm{H}_{5} \mathrm{Cl} \quad \mathrm{C}_{6} \mathrm{H}_{5} \mathrm{Cl} \quad \mathrm{C}_{6} \mathrm{H}_{5} \mathrm{Cl}$

\section{SOLUTE IN GAS PHASE}

$\Delta_{\text {solv }} H^{\mathrm{A} / \mathrm{C} 6 \mathrm{H} 4 \mathrm{Cl} 2}$

$\mathrm{C}_{6} \mathrm{H}_{4} \mathrm{Cl}_{2} \quad \mathrm{C}_{6} \mathrm{H}_{4} \mathrm{Cl}_{2} \quad \mathrm{C}_{6} \mathrm{H}_{4} \mathrm{Cl}_{2}$

$\mathrm{C}_{6} \mathrm{H}_{4} \mathrm{Cl}_{2} \quad \mathrm{C}_{6} \mathrm{H}_{4} \mathrm{Cl}_{2} \quad \mathrm{C}_{6} \mathrm{H}_{4} \mathrm{Cl}_{2}$

$\mathrm{C}_{6} \mathrm{H}_{4} \mathrm{Cl}_{2} \quad \mathrm{C}_{6} \mathrm{H}_{4} \mathrm{Cl}_{2} \quad \mathrm{C}_{6} \mathrm{H}_{4} \mathrm{Cl}_{2}$

$\mathrm{C}_{6} \mathrm{H}_{4} \mathrm{Cl}_{2} \quad \mathrm{C}_{6} \mathrm{H}_{4} \mathrm{Cl}_{2} \quad \mathrm{C}_{6} \mathrm{H}_{4} \mathrm{Cl}_{2}$ 